\title{
Investigation of the Role of Crown Crack in \\ Cohesive Soil Slope and Its Effect on Slope Stability Based on Extended Finite Element Method
}

Yiding Bao ( $\sim$ baoyd17@mails.jlu.edu.cn )

Institute of Mountain Hazards and Environment

Yuchao Li

Jilin University

Yansong Zhang

Jilin University

Jianhua Yan

Jilin University

Xin Zhou

Chongqing Jiaotong University

\section{Research Article}

Keywords: XFEM, stability analysis, crown crack, crack propagation, stress status

Posted Date: May 18th, 2021

DOI: https://doi.org/10.21203/rs.3.rs-529550/v1

License: (9) This work is licensed under a Creative Commons Attribution 4.0 International License. Read Full License

Version of Record: A version of this preprint was published at Natural Hazards on July 30th, 2021. See the published version at https://doi.org/10.1007/s11069-021-04947-8. 
Investigation of the role of crown crack in cohesive soil slope and its effect on slope stability based on extended finite element method

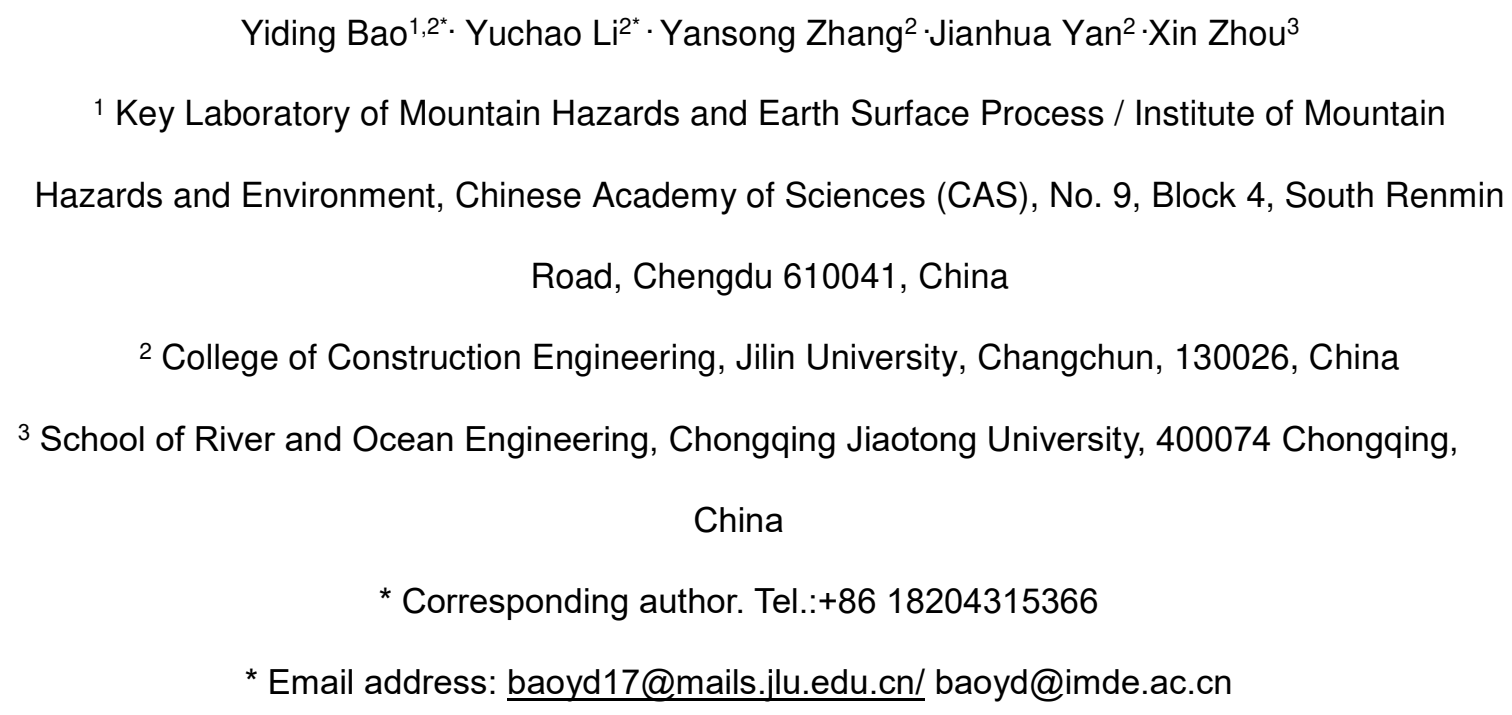

\section{Abstract}

Tensile cracks in soil slopes, especially developing at the crown, have been increasingly recognized as the signal of slope metastability. In this paper, the role of crown cracks in natural soil slopes was investigated and their effect on stability was studied. A numerical slope model based on the extended finite element method (XFEM) simulating the tensile behavior of soil was used. Before the simulation, a numerical soil tensile test was applied to validate the use of XFEM on tensile behavior of soil. Slope failure was simulated by using strength reduction technique, which can determine the potential slip surface of slope. The simulation results show that the crown crack forms in natural soil slopes when the plastic zone starts penetrating, and therefore it is reasonable to consider the crown crack as the signal of slope metastability. A sensitivity analysis shows that cracks are at the position of the tension zone or very long can obviously affect the slope stability. The stress variation analysis from the initial deformation to slip surface penetration shows that the slope is at a state of compressive stress initially. When plastic zone starts to penetrate, the upper part of slope generates tension zone, but the extent of tension zone is limited until slope failure. This shows why tensile cracks are difficult to form 
and be stretched in the deep part of the slope. The application of XFEM on slope stability analysis can be used to assess the tensile strength of soil and predict slope failure disaster.

Keywords: XFEM, stability analysis, crown crack, crack propagation, stress status

\section{Introduction}

Landslides are one of the most common geological disasters in nature. Many catastrophic landslides occur all over the world each year, causing loss of property and life (Tang et al., 2009; Yin et al., 2016; Gianvito et al., 2018; Chen et al., 2018b; Zhang et al., 2019a;). Landslide is a form of mass movement, including diverse ground movements such as fall, topple, slide, spread, and flow (Hungr et al., 2014). All these types of ground movements exhibit mass separation behavior, generating cracks before mass separation. Some landslide events has exhibited the whole process of failure (Fan et al., 2018; Ouyang et al., 2019; Chen et al., 2019), and one typical case is the Baige landslide. Researchers applied remote-sensing images and InSAR to the Baige landslide, to analyze its historical deformation (Xu et al., 2018; Ouyang et al., 2019). They found deformation firstly occurred at the front part of the slope at the initial stage of the deformation; then as time goes on, large-scale tensile cracks and drop heads formed at the slope crown; finally, with deformation developing, a slide occurred.

The case shows a common failure process of landslides. Although, many landslide events (Steiakakis et al., 2009; Chen et al., 2018a; Tang et al., 2019; Fan et al., 2019) and field investigations (Fig.1) have proven that crown cracks are the signal of slope metastability during the long-term slow deformation process, there are still some issues deserve researching, such as at what stage of slope deformation will the crown cracks form? How do these cracks form? What's the maximum length the crack can be? Do these cracks affect the slope stability? Although landslide laboratory tests have been carried out to answer some of them (Tang et al., 2019), some data cannot be easily acquired from the laboratory tests, limiting exploring these questions. Questions such as why 
the depth of a crack cannot develop downward without limitation are still unexplained. Knowing the answer of these questions is important for comprehending landslide behavior as well as the landslide prevention.

Numerical simulation can help researchers obtain extra data, which is not available in laboratory tests. Nowadays, the most common methods to evaluate slope stability with cracks are the limit equilibrium method (LEM) (Bishop 1973; Seed et al., 1990; Koerner and Soon, 2000) and finite element method (FEM) (Griffiths and Lane., 1999; Qu et al., 2009; Bao et al., 2019; Lei et al., 2021). In addition, some new methods such as discrete element method (DEM) (Zhou et al., 2009; Bao et al., 2020), smoothed particle hydrodynamics (SPH) (Li et al., 2019; Ray et al., 2019), and material point method (MPM) (Liu et al., 2019; Conte et al., 2019) have been developed for analyzing slope stability as well as the post-failure movement. The analysis of slope stability using these new methods mainly depends on the strength reduction technique, and they have advantages for the analysis of large-deformation issues. However, these methods still have some limitations in stability analysis. In the DEM, the behavior of the material depends on the interactions between particles. It's difficult to measure some of microscopic parameters between particles, and there is no strong theory to illustrate relationship between the magnitude of macroscopic and microscopic parameters. Thus, it is very time-consuming to determine proper parameters, especially in the strength reduction progress. The SPH and MPM are also timeconsuming compared to LEM and FEM. The computation accuracy of SPH as well as MPM is lower than FEM in the small deformation process before slope failure. And although these new methods can be used for slope stability analysis in theory, they lack large amounts of engineering validation compared to LEM and FEM, especially in the case involving cracks. As for the LEM, it is a classical method which has been used for the slope stability analysis involving cracks (Michalowski 2012; Michalowski 2013; Tang et al., 2019). However, there are many limitations in the LEM to analyze a problem with cracks. Cracks in the LEM can only be used for the calculation of factor of safety (FOS). Cracks need to be pre-set in the model, and cannot be updated with 
calculations. And slope deformation cannot be shown in the LEM. FEM can overcome these shortcomings in the LEM, which makes it a better choose for slope stability analysis involving cracks.

The conventional FEM (CFEM) is difficult to be used to simulate discontinuous elements such as cracks due to meshing limitation. To overcome the shortcomings of CFEM in the discontinuous analysis, some theories including the efficient remeshing techniques (Areias et al., 2013; 2015), the numerical manifold method (Shi 1991; Ma et al., 2009), and the extended FEM (XFEM) (Moës et al., 1999) are proposed. Most of the methods modelling crack propagation by FEM heavily depend on the mesh alignment (Rabczuk and Ren, 2017), but the XFEM can avoid the problem. In XFEM, special functions and element segmentation method are used to fuse to solve the solution of finite element approximation. And the level set method is used to show the geometry and extension process of the discontinuous interface. Different from the CFEM, XFEM no longer has strict requirements on the accuracy and repetition of the network, and has no specific restrictions on the crack front and growth path. And XFEM has high computational efficiency. Therefore, this method has been widely applied in fracture mechanics and engineering (Sanborn and Jean H, 2011; Wang et al., 2015; Zhou and Chen, 2019).

In this study, to investigate the role of crown cracks in soil slope, XFEM based on ABAQUS software was used for the simulation of tensile behavior in soil. The authors set a series of numerical simulation to explore the formation of crown cracks and the effect of a tensile crack on soil slope stability. Factors, including the position, strength, and depth of cracks were considered for sensitivity analysis, and combined with stress analysis, some interesting phenomena were found with conclusions made. 


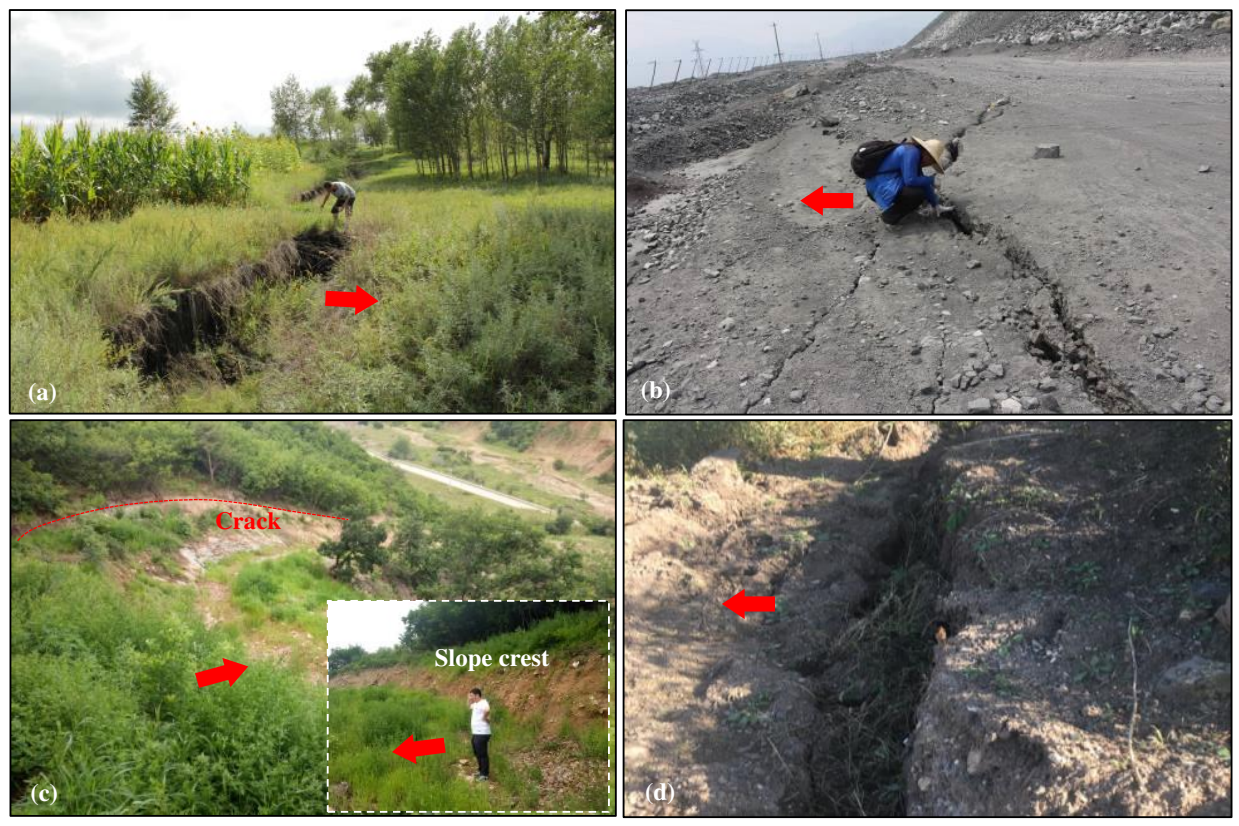

Fig. 1. Crown cracks appear in some soil slopes. (a) A potential landslide with obvious deformation in Jilin province in 2016, (b) a potential landslide in a waste dump in Sichuan province in 2016, (c) a potential landslide with obvious deformation in Jilin province in 2015, and (d) a potential landslide in Liaoning province in 2019. Red Arrows denote to the direction of slides.

\section{Methodology}

\section{XFEM}

The extended element method (XFEM) is an improvement on FEM for the research of discontinuous processes, such as cracks. It is proposed by the Ted Belytschko team (Moës et al., 1999). In the XFEM, a special enrichment function is used for the discontinuity. When the enrichment function is applied to crack analysis, it can well fit the asymptotic function of the tip, and has a good expression for the displacement jump on the crack surface. The standard extended finite element approximate equivalent equation of $u$ function in ABAQUS:

$$
\sum_{I=1}^{N} N_{I}(x)\left[u_{I}+H(x) a_{I}+\sum_{\alpha=1}^{4} F_{\alpha}(x) b_{I}^{\alpha}\right]
$$

In equation (1), $N_{I}(x)$ is the normal shape function of the node. The first term on the right of the equal sign is available for all nodes, and it is related to the continuous part of finite element. The definition of $u_{I}$ is the displacement vector of the normal node. The second term applies to particular nodes, such as a shape 
function that supports a node cut inside a crack. The term is the product of nodal enriched degree of freedom vector $a_{I}$, and $H(x)$ denotes to the jump function across the discontinuous interface. The third term is the most limited, only for the shape function supporting the node cut off by the crack tip. The term is the product of nodal enriched degree of freedom vector $b_{I}^{\alpha} . F_{\alpha}(x)$ describes the elastic asymptotic properties of the crack tip. The jump function $H(x)$ is described as follows.

$$
H(x)=\left\{\begin{array}{ccc} 
& 1 & \text { if }\left(x-x^{*}\right) \cdot n \geq 0 \\
-1 & \text { otherwise }
\end{array}\right.
$$

Where, $x$ represents the sampling point; $x^{*}$ represents the point with the shortest distance from $x$ on the crack; $\mathrm{n}$ represents the unit vector of the crack outward normal at $x^{*}$.

Fig. 2a shows the asymptotic function of crack tip in isotropic elastic material, and the formula is:

$$
F_{\alpha}(x)=\left[\sqrt{r} \sin \frac{\theta}{2}, \sqrt{r} \cos \frac{\theta}{2}, \sqrt{r} \sin \theta \sin \frac{\theta}{2}, \sqrt{r} \sin \theta \cos \frac{\theta}{2}\right]
$$

In equation $(3),(r, \theta)$ is polar coordinate representation, whose physical meaning is that the origin is at the crack tip.

The node subset $I^{*}$ is the set of all nodes of elements cut by discontinuities. The global enrichment function can only work in those elements whose nodes are all in the subset, $I^{*}$. The level set function is a scalar function whose zero-level represents discontinuity. The level-set function $\phi(x)$ which is described as follows determines whether an element is cut by discontinuities.

$$
\text { cut element: } \min \left(\phi_{i}\right) \max \left(\phi_{i}\right)<0\left(i \in I^{e l}\right)
$$

$$
\text { uncut element: } \min \left(\phi_{i}\right) \max \left(\phi_{i}\right)>0\left(i \in I^{e l}\right)
$$

$$
\phi(x)= \pm \min _{\forall x_{\Gamma} \in \Gamma}\left\|x-x_{\Gamma}\right\|, \quad \forall_{x} \in \Omega
$$

In the above equation $I^{e l}$ represents the set of element nodes.

The domain $\Omega$ is divided by the discontinuity into $\Omega_{\mathrm{P}}{ }^{+}$and $\Omega_{\mathrm{P}}{ }^{-}$, and the level set function can be positive or negative on either side of the discontinuity, respectively. In the domain $\Omega$, the phantom node is used to 
describe the cracked behavior, and the node is initially superimposed on the real node before element separation.

When there is no crack in elements, the phantom node corresponds to real nodes with completely constraint. If the element is divided by the discontinuity into two parts, corresponding phantom nodes and real nodes will separate, and no longer be tied together (Fig.2b). They are then interpolated by standard finite element shape functions:

$$
\phi^{h}(x)=\sum_{i \in I} N_{i}(x) \cdot \phi_{i}
$$

where $h$ is the number of interpolated elements.
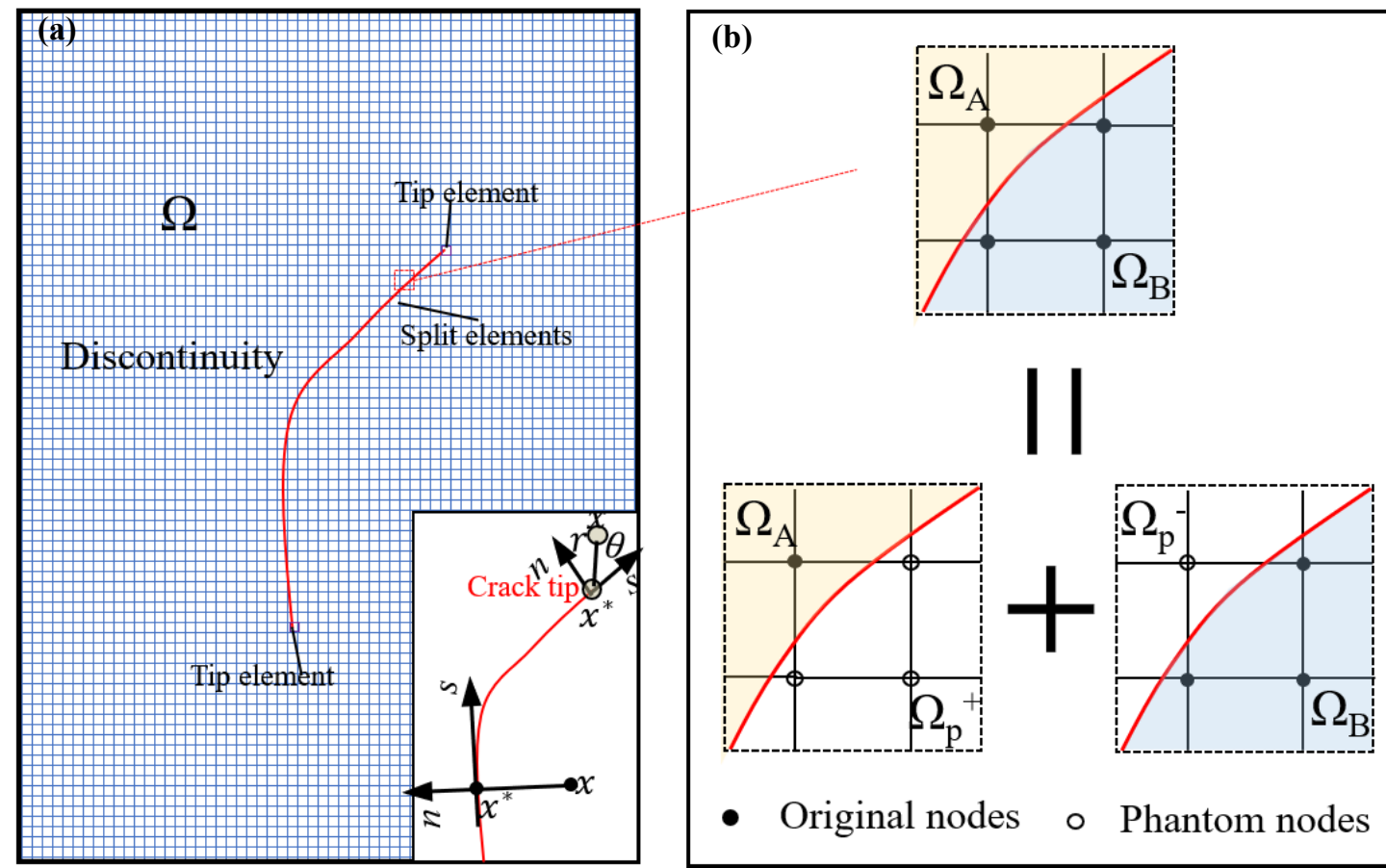

- Original nodes $\circ$ Phantom nodes

Fig. 2. Principles of the extended element method. (a) Sketch of a discontinuous element in the XFEM, (b) illustration of phantom node method.

Tensile strength of soil

Tensile cracks are generated by soil stretching (Fig. 3a), and Fig.3b shows a typical stress-displace curve of the tension process. Previous studies on tensile test for soil (Hadas and Lennard, 1988) show that a tensile crack forms when the tensile stress $\left(\sigma_{\mathrm{t}}\right)$ reaches the tensile strength $\left(f_{\mathrm{t}}\right)$. Before $\sigma_{\mathrm{t}}$ reaches $f_{\mathrm{t}}$, the $\sigma_{\mathrm{t}}$ constantly increases with tensile displacement $(\triangle l)(\mathrm{AB}$ segment in Fig. 3b). In this stage, the tensile displacement 
consists of elastic-plastic deformation of soil $\left(\triangle l_{1}+\Delta l_{3}\right.$ in Fig. 3a). When $\sigma_{\mathrm{t}}$ reaches $f_{\mathrm{t}}$ (point B in Fig. 3b), the soil is damaged and a crack forms. The start of damage leads to stress accumulation at the damaged part. And then, the accumulated stress is continuously released along the crack, causing crack propagation and opening. In this stage, $\sigma_{\mathrm{t}}$ decreases with the increase in $\triangle l$ (BC segment in Fig. 3b), and the tensile deformation mainly consists of a crack opening, until the crack opening reaches the maximum value $\left(\triangle l_{2}\right.$ in Fig. 3a). Finally, the soil body is completely separated (point C in Fig. 3b).
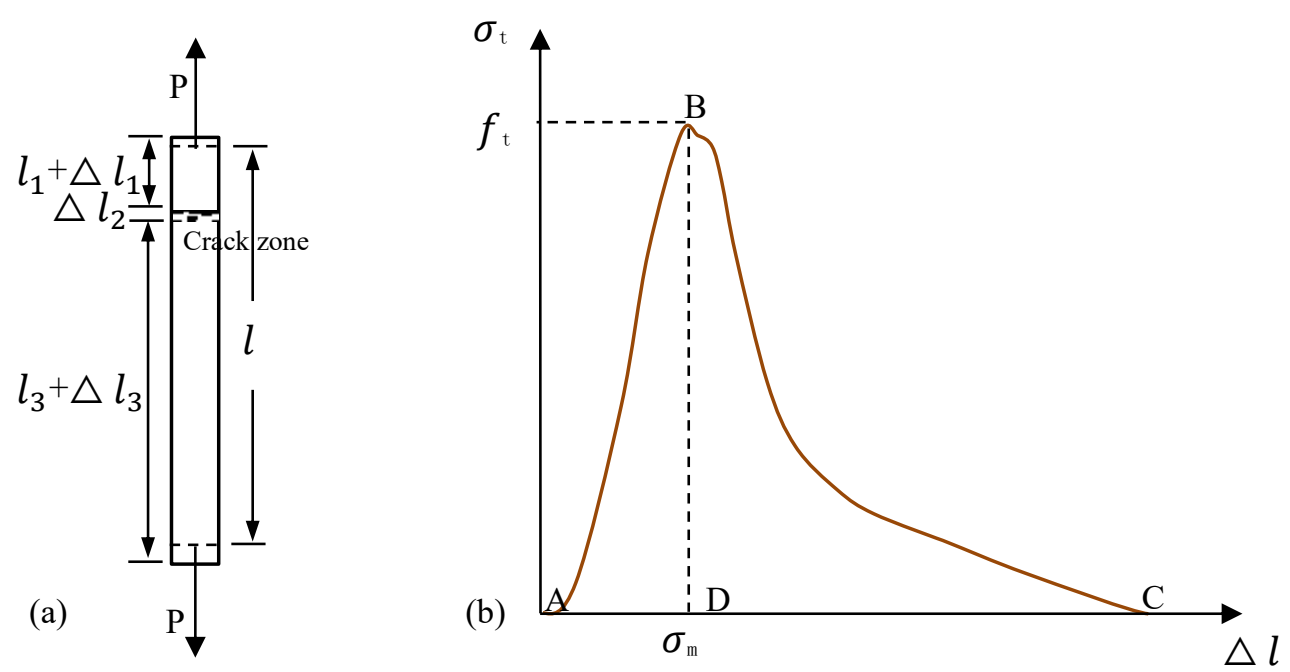

Fig. 3. Mechanical characteristics of the tensile crack of soil. (a) A sketch of tensile failure of materials, (b) an example of tensile stress-displacement curve of soil (modified from Tamrakar et al., 2005). MAXPS criterion, no crack is generated until the maximum principal stress reaches a certain value; therefore, the value can be set as $\sigma_{\mathrm{t}}$ for the soil. The criterion of MAXPS can be expressed as follows: initiated after the maximum principle stress reaches $\sigma_{\text {max }}^{o}$. 
and the evolution of an existing crack depends on the softening stage of the soil (BC segment in Fig. 3b).

ABAQUS has two types of ways to define the softening stage: defining the maximum crack opening or fracture energy. When ignoring the plastic deformation during the cracking stage, the maximum crack opening can be considered as the length of DC segment, whereas the fracture energy can be considered as the area of DBC siege per length of material. The shape of softening phase curve (BC segment) can be specified by determining the form of index or discrete point data.

The composition of a soil slope usually includes clay, silt, sand, and gravel, considered as soil aggregates. To determine tensile parameters of soil aggregates, the authors studied some literature about tensile strength (Causarano et al., 1993; Hadas and Lennard, 1988; Munkholm et al., 2002; Tamrakar et al., 2005; Zhang et al., 2006) and found that their tensile strength usually ranges from several kilopascal to tens of kilopascal for soil aggregates (Table 1). Many factors such as density, water content, composition, and porosity affect the tensile properties of soils. In this paper, the authors used the stress-strain curve reported in Tamrakar's research (Tamrakar et al., 2005) as a typical stress-strain curve (Fig. 3b) and applied it to all the simulation where damage evolution was attenuated in a quadratic form.

Table 1. A brief summary for tensile strength of soil aggregates

\begin{tabular}{|c|c|c|c|c|c|c|c|}
\hline Material & Composition & $\begin{array}{l}\text { Density } \\
\left(\mathrm{kg} / \mathrm{m}^{3}\right)\end{array}$ & $\begin{array}{c}\text { Water } \\
\text { content } \\
(\%)\end{array}$ & $\begin{array}{c}\text { particle } \\
\text { diameter } \\
(\mathrm{mm})\end{array}$ & $\begin{array}{l}\text { Tensile strength } \\
\text { (kPa) }\end{array}$ & $\begin{array}{c}\text { Maximum crack } \\
\text { opening (mm) }\end{array}$ & references \\
\hline \multirow{7}{*}{$\begin{array}{c}\text { Soil } \\
\text { aggregates }\end{array}$} & $\begin{array}{l}\text { Clay-sand } \\
\text { mixtures }\end{array}$ & 1440 & 10 & $0.001-1$ & 9 & 0.2 & $\begin{array}{c}\text { Tamrakar et } \\
\text { al., } 2005\end{array}$ \\
\hline & & & & & $2.0-$ & & \\
\hline & Sandy loam & $\begin{array}{l}1410- \\
1570\end{array}$ & 30 & $2-16$ & $\begin{array}{c}3.2 \text { (compacted) } \\
10-15 \text { (non- }\end{array}$ & & $\begin{array}{c}\text { Munkholm et } \\
\text { al., } 2002\end{array}$ \\
\hline & & & & & compacted) & & \\
\hline & Sandy loam & 1 & $5-20$ & 1 & $10-25$ & & $\begin{array}{c}\text { Causarano et } \\
\text { al., } 1993\end{array}$ \\
\hline & $\begin{array}{l}\text { Compacted } \\
\text { gravel soil }\end{array}$ & $\begin{array}{l}1900- \\
2200\end{array}$ & $16.3-19.3$ & 1 & $30-80$ & & $\begin{array}{c}\text { Zhang et al., } \\
2006\end{array}$ \\
\hline & Fine sand & $\begin{array}{l}2100- \\
2200\end{array}$ & $3-35$ & $0.01-1$ & $0.26-1.2$ & 0.02 & Cai et al., 2017 \\
\hline
\end{tabular}


To evaluate whether XFEM can well analyze the behavior of tensile crack in soil, a numerical tensile test was performed to calibrate it. The tensile test is referred from Tamrakar's study (Tamrakar et al., 2005). In the test, a compacted clay-sand mixture specimen was stretched using a steel tensile mold at a steady velocity (Fig. 4a). The physical parameters of material were obtained from the research, whereas the damage parameters of soil were obtained from the stress-displacement curve $\left(\sigma_{\max }^{o}=10 \mathrm{kPa}\right.$, the maximum crack $\left.=0.2 \mathrm{~mm}\right)$. The results show the progress in crack propagation generated by stretching, and the final figure of crack in the

169 simulation is consistent with the laboratory test (Fig. 4b-e), indicating that XFEM can well simulate the tensile cracks in soil. 

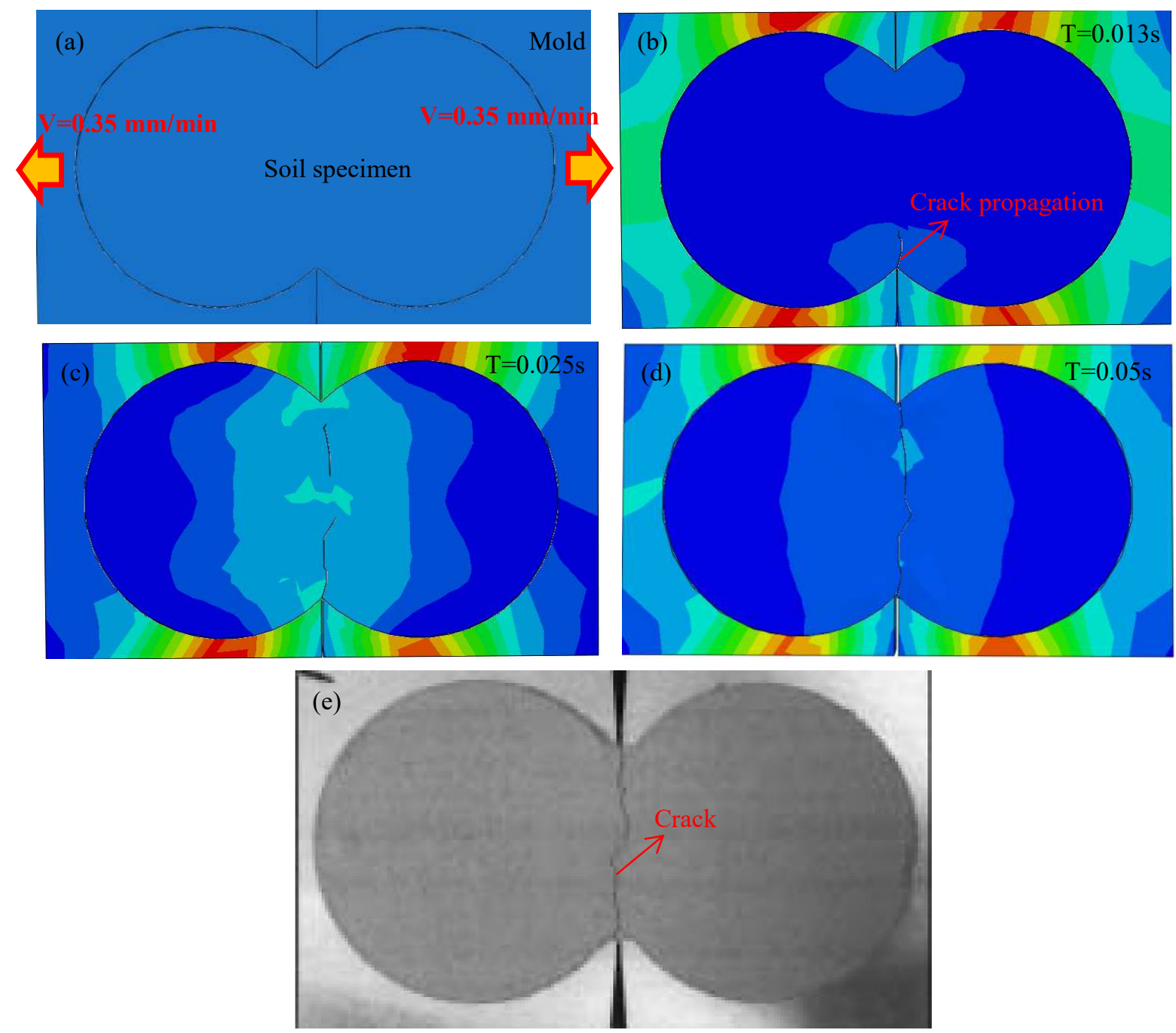

Fig. 4. Comparison result of real and simulation tensile tests. (a)-(d) Propagation of crack during the stretching based on the stress result, (e) tensile test in Tamrakar's study (Tamrakar et al., 2005).

\section{Results and discussion}


modulus $)=40 \mathrm{MPa}$ from Bao's literature of soil aggregates (Bao et al., 2019a); the tensile stress-strain curve was adopted from Tamrakar's research and corresponding damage parameters of the soil were taken a relative small value as $\sigma_{\max }^{o}=1 \mathrm{kPa}$ and the maximum crack opening $=0.02 \mathrm{~mm}$. The stability of slope without XFEM element and the slope using XFEM with an internal crack were calculated.

In the simulation, the failure of slope relied on the strength reduction technique (Matsui and San, 1992) and the strength reduction factor (SRF), which have been widely applied to determine the potential slip surface of a slope (Niant et al., 2012; Jiang et al., 2015; Bao et al., 2020). The phenomenon that plastic zone extends from the toe to the upper of the slope was treated as the signal of failure (Shen and Karakus, 2014). Failure criterion of the Mohr-Coulomb strength criterion was adopted for the material.

Figs. 5b-e show the results of stability analysis. After the strength reduction, the plastic strain zone expands from the slope toe to upper. When plastic deformation reaches the position of internal crack, stress is transmitted along the crack to the crack tip and causes stress accumulation. Stress at the tip of crack constantly increases until it reaches the value of $\sigma_{\max }^{o}(1 \mathrm{kPa})$, causing crack propagation to the upper of slope. The FOS of slope without crack is 1.298 , whereas the FOS of slope with an internal crack is 1.281 . From this simple case, it can be considered that the cracks in the slope might affect the shape of potential slip surface and even the value of FOS. In the following sections, we discuss several factors, including the position, strength, and depth of cracks that might affect the stability of slope based on the above model. 


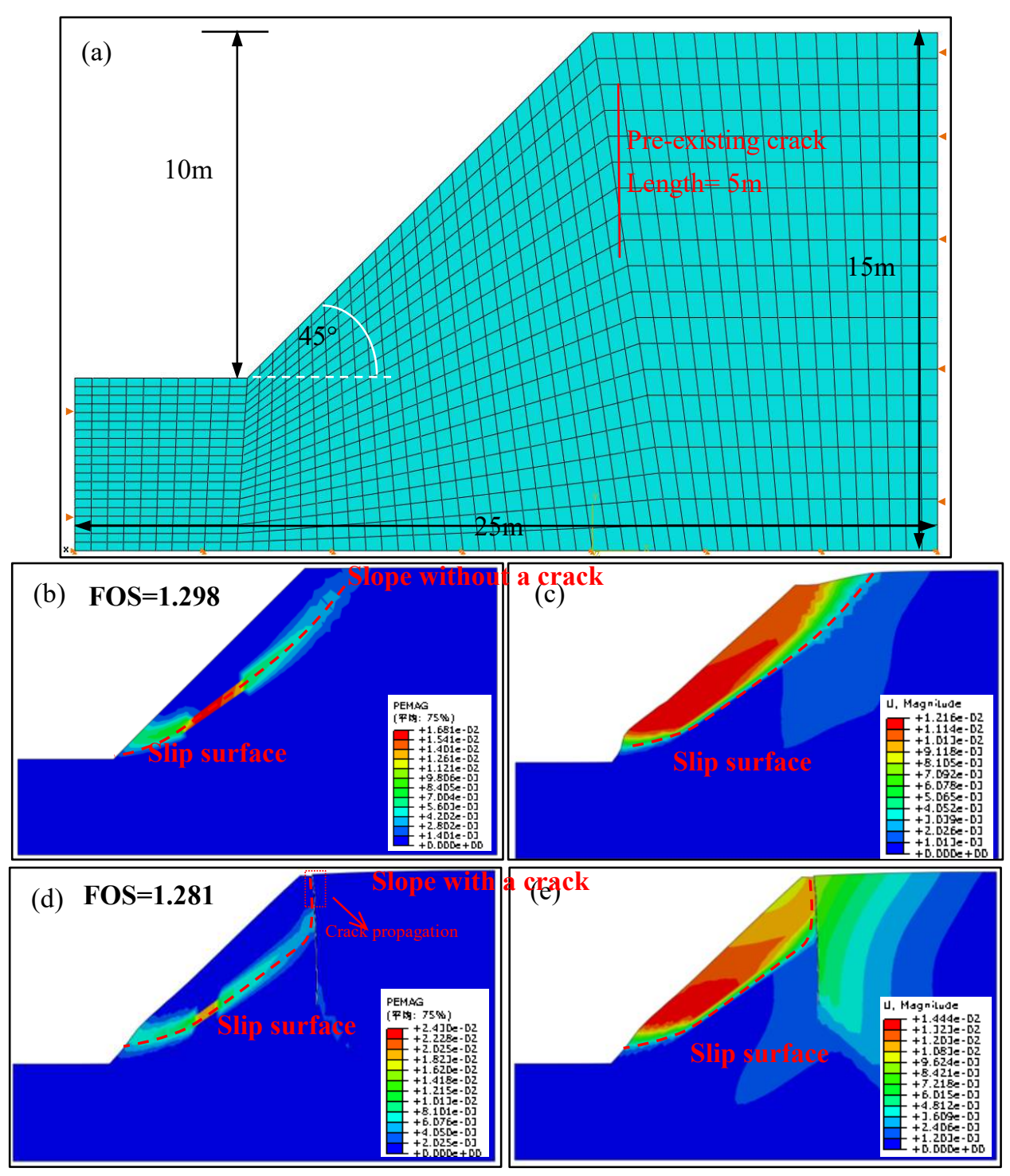

Fig. 5. Results of stability analysis. (a) Dimensions of the slope model, (b) and (d) magnitude of the plastic strain, (c) and (e) magnitude of the total displacement.

Sensitivity analysis

Fig. 6 shows the strength reduction of a slope without a pre-existing crack element when $\sigma_{\max }^{o}$ is equal to $5 \mathrm{kPa}$. The simulation result is consistent with the field investigation of most soil landslides. After strength reduction, the slope is deformed towards the free surface with slope toe swelling (Fig.6a). Then a part of the soil at the upper of slope gradually changes from compressive stress state to tensile stress state (Fig. 6d). When the maximum tensile principal stress in the tension zone reaches the damage condition, damage starts (Figs. 6e and $\mathrm{f}$ ). The crack is formed at the slope crown, and the soils present on both sides of the crack have an obvious 
typical failure mode of soil slopes in nature and proves that the crown crack is a signal of metastability.
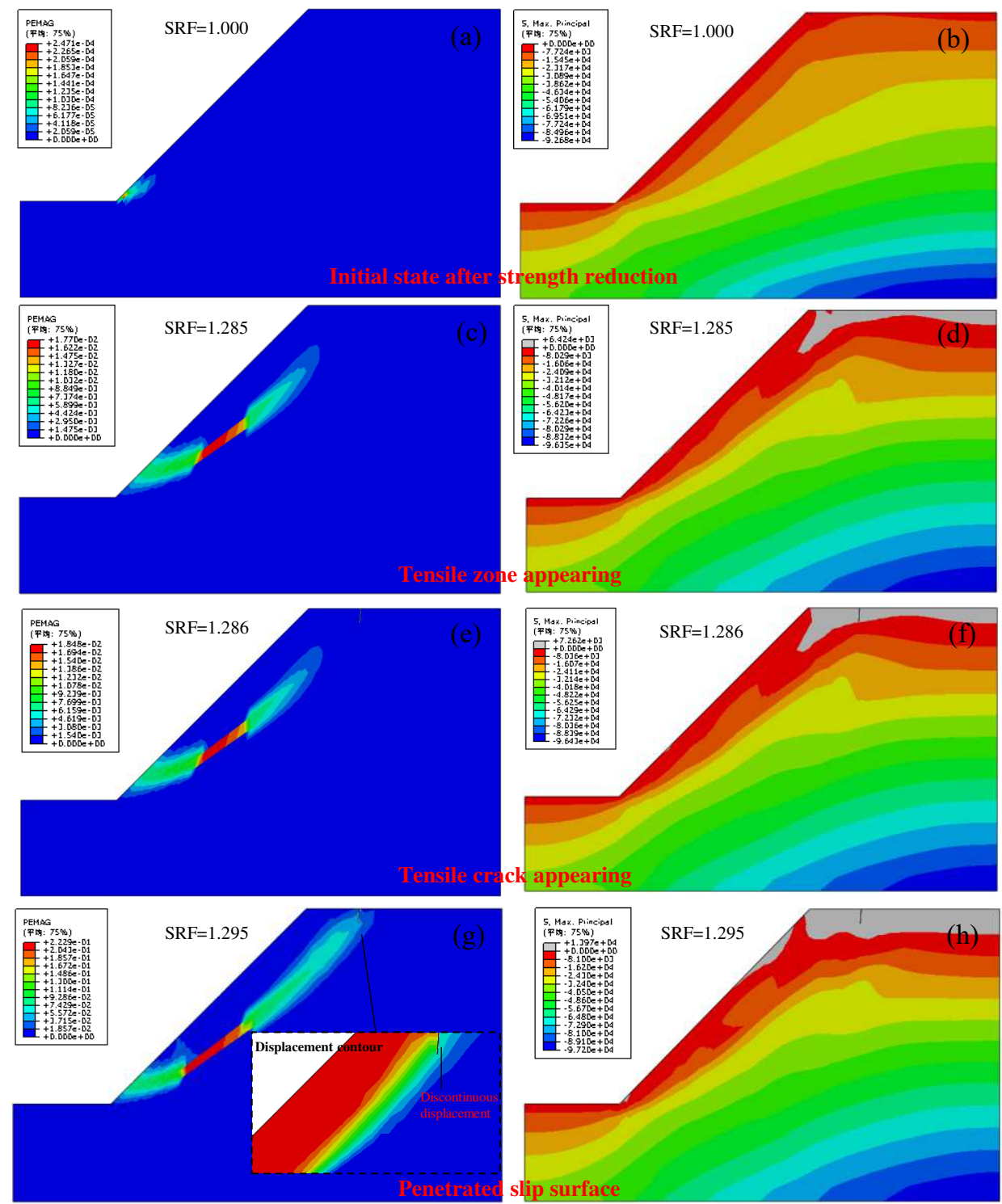

Fig. 6. Propagation of a tensile crack in a soil slope failure. (a), (c), (e), and (g) incorporate the contour map of plastic strain magnitude; (b), (d), (f), and (h) incorporate the contour map of maximum principal stress.

It's worth noting that the tensile crack appears and completely opens at the slope crown before the slip

surface is penetrated (Fig. 6e and f). This means the length of shearing path of the slip surface is shorter than the entire length of slip surface, because the crack occupies a certain length of the slip surface. If a model does not consider tension effect or tensile cracks (e.g.: the conventional LEM assumes that the entire slip surface is generated by shear effect), the FOS calculated will be slightly larger than the real value. In the FEM simulation 
of our case, the FOS of the slope is 1.298 when the plastic zone is completely penetrated without the XFEM element, while the FOS is 1.295 when the plastic zone extends to the bottom of the tension crack with the XFEM element.

In addition, the authors found the damage parameters of soil affect crack generation (Fig. 7). When the value of $\sigma_{\max }^{o}$ is less than $4 \mathrm{kPa}$, the crack forms inside the potential failure mass (Figs. $7 \mathrm{a}$ and $\mathrm{c}$ ), and the displacement of soil on both sides of crack is continuous at the time of slope failure (Figs. $7 \mathrm{~b}$ and d). When the value of $\sigma_{\max }^{o}$ is more than $7.5 \mathrm{kPa}$, no crack is generated at the time of slope failure (Figs. $7 \mathrm{~g}$ and $\mathrm{h}$ ). Both the situations are not consistent with field investigation and common sense, and seldom occur in reality (Tang et al., 2019); thus, they are considered unreasonable. Only when the value of $\sigma_{\text {max }}^{o}$ ranges from $4 \mathrm{kPa}$ to 7.5 $\mathrm{kPa}$, the simulation results such as Fig. 7e and Fig. 7f are consistent with the landslide field study. This phenomenon can be attributed to soil strength. Bonds and friction exist between soil particles. They are expressed as internal friction and cohesion in shearing, whereas they are expressed as tensile strength in tension. Therefore, the tensile strength of soil is not completely independent of other strength parameters such as shear strength. In the simulation, the value of cohesion is taken as $10 \mathrm{kPa}$ while the internal friction is taken as $34^{\circ}$, indicating that $\sigma_{\max }^{o}$ is a moderate value which is not too small or large. In other words, the tensile strength of field soil in the scale of $4 \mathrm{kPa}$ to $7.5 \mathrm{kPa}$ is also moderate and appropriate. Although the relationship between shear and tensile strength of soil requires more study, this speculation is supported by the results of numerical simulation. This provides a new calibration idea to roughly estimate the tensile strength of soil, especially for the field test which is difficult to conduct in a laboratory. 

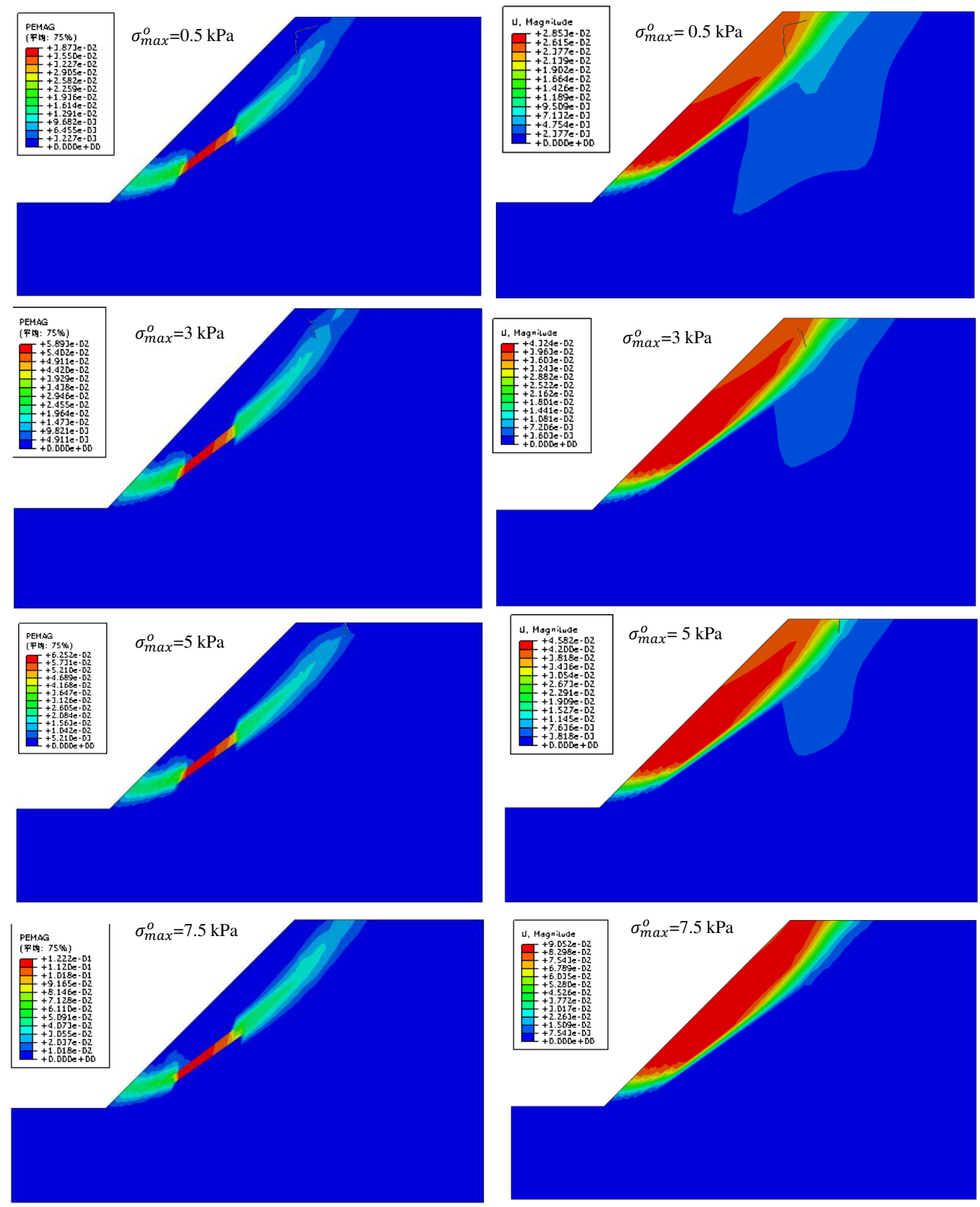

Fig. 7. Morphology of tensile crack at the time of a slope failure under different soil damage strengths. (a), (c), (e), and (g) the magnitude of plastic strain; (b), (d), (f), and (h) the magnitude of total displacement.

Besides the crown cracks, other types of tensile cracks generated by cycles of wetting and drying (Konrad and Ayad, 1997), weathering (Hales and Roering, 2007), and desiccation (Peron et al., 2009) usually appear in a slope. To explore whether tensile cracks affect stability of slope, six groups of numerical tests were set for various situations, including the crack is located at the position of trailing edge, inside the potential failure zone, and out of the potential failure zone (Fig.8). Considering that the strength of damage parameters might affect the outcome, five groups of strength data that represent the very low, low, medium, high, and very high tensile 
strength were used in the computation. $\sigma_{\max }^{o}$ was taken as $0.5,2,5,20$, and $50 \mathrm{kPa}$, and the corresponding maximum crack opening was taken as $0.01,0.04,0.1,0.4$, and $1 \mathrm{~mm}$, respectively, according to Fig.3b. Fig.9af show the contour map of stress magnitude corresponding to Fig8a-f.

Fig. 8a shows the situation of a slope with a crack at the slope crown. The results show that the crack at the slope crown hardly affects the stability of slope regardless of the strength of crack. This is probably because the length of soil that can be sheared is very short at the slope crown, or the pre-existing penetrating crack releases the accumulated stress and strain to the ground surface. Fig. $8 \mathrm{~b}$ shows the situation of a slope with a crack outside the potential failure zone. The results show that it is difficult for the tensile crack to affect the stability of slope regardless of the length of crack and tensile strength of soil. Fig. 8c shows the situation of a slope with a crack inside the potential failure zone. The results show that when the crack is very short and leaves some distance to the potential plastic zone, it does not affect slope failure. When the crack is short but located at the position of the potential plastic zone (Fig. 8d), it still generally does not affect the slope stability regardless of the tensile strength of soil. This is because shearing is the mainly effect at this part of the slip surface, and the phenomenon indicates this part of slope is at the compressive state. Fig. 8e shows a tensile crack with relatively small damage parameters $\left(\sigma_{\max }^{o}=2 \mathrm{kPa}\right)$ that is at the upper part of potential slip surface. Compared to Fig. $8 \mathrm{~d}$, the crack can be stretched to propagate to the ground surface after strength reduction. This is probably because one tip of the crack is located at the tension zone (referring to Fig. 6h), changing the shape of original slip surface and FOS in a smaller scale. One tip of the crack transmits stress, whereas the other tip accumulates stress during strength reduction, and it determines the direction of propagation. When the crack propagates to the ground surface, the accumulated stress is completely released (Fig. 9e). When the damage parameter $\left(\sigma_{\max }^{o}=50 \mathrm{kPa}\right)$ is larger than the maximum tensile principal stress $(13 \mathrm{kPa})$, the crack is not stretched, and the potential slip surface does not change. Fig. $8 \mathrm{f}$ shows when a crack is much longer than the depth of original slip 
surface, the presence of a crack causes stress redistribution after strength reduction, thus completely changing the original stress state and original potential slip surface (Fig. 9f).

Above all, the existence of cracks will cause discontinuities in stress (Fig.9). A crack completely buried underground will transmit stress on one tip, and accumulates stress on the other tip. If one tip of a crack propagates to the ground surface, all the accumulated stress will be released. Whether the tensile crack is pulled apart or not depends on the maximum tensile stress. According to the simulation, except the tension zone located on the upper of slope, the slope is generally at a compressive state, and it is difficult for a short-medium tensile crack in the compressive zone to change the original stability. Only a long tensile crack passed through the plastic zone, indicating that a large scale of stress redistribution will change the original stability.
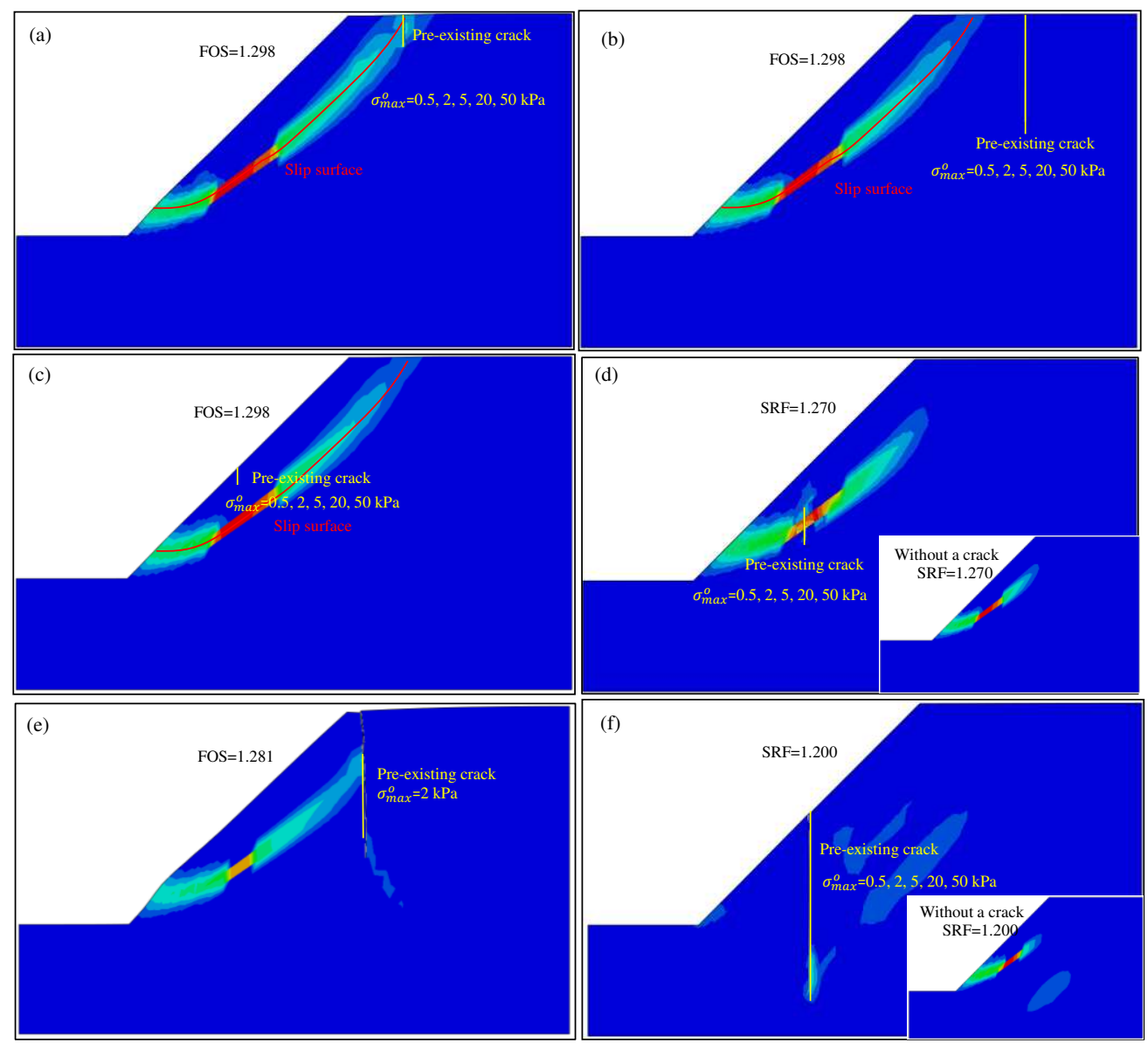

Fig. 8. Sensitivity analysis for crack propagation in different conditions based on the contour map of plastic strain magnitude. 


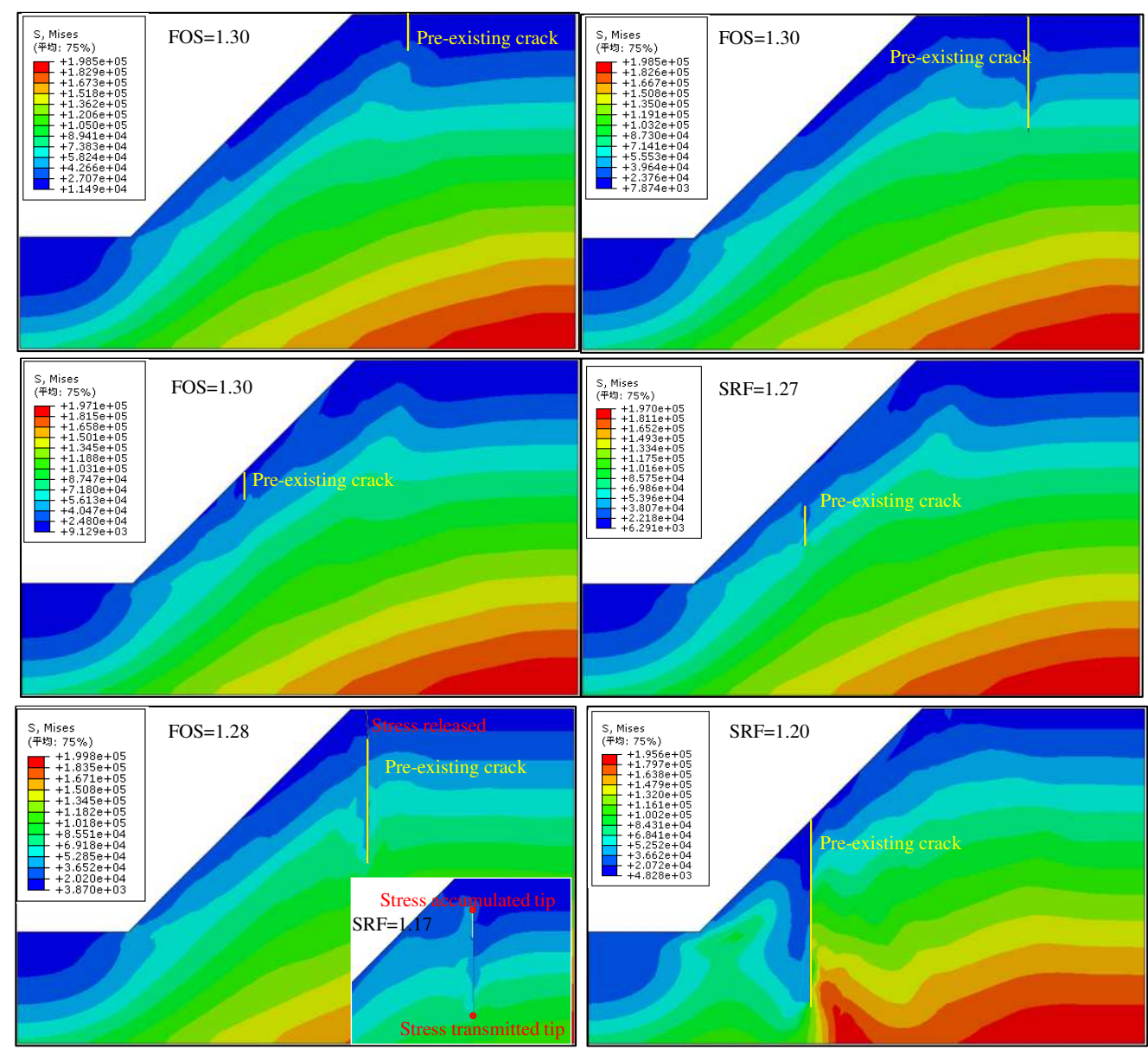

Fig. 9. Sensitivity analysis for crack propagation in different conditions based on the contour map of stress magnitude.

To determine the stress variation in slope from the initial deformation to failure, six nodes at different parts of the slope were set to monitor the corresponding information (Fig. 10a). The maximum principal stress, normal stress in the horizontal direction (s11), normal stress in the vertical direction (s22), and shear stress (s12) were recorded. Fig. 10b shows when SRF is less than 1.25 , the maximum principal stress is less than zero, and the variation is very small with the increase in SRF value. In this scale of SRF, the slope is at a compressive state, and no tensile crack is generated. When SRF is larger than 1.25 , the maximum principal stress of the upper of slope increases to a value of $\sim 10 \mathrm{kPa}$, generating tensile cracks at the slope crown. Fig. 10c shows the 


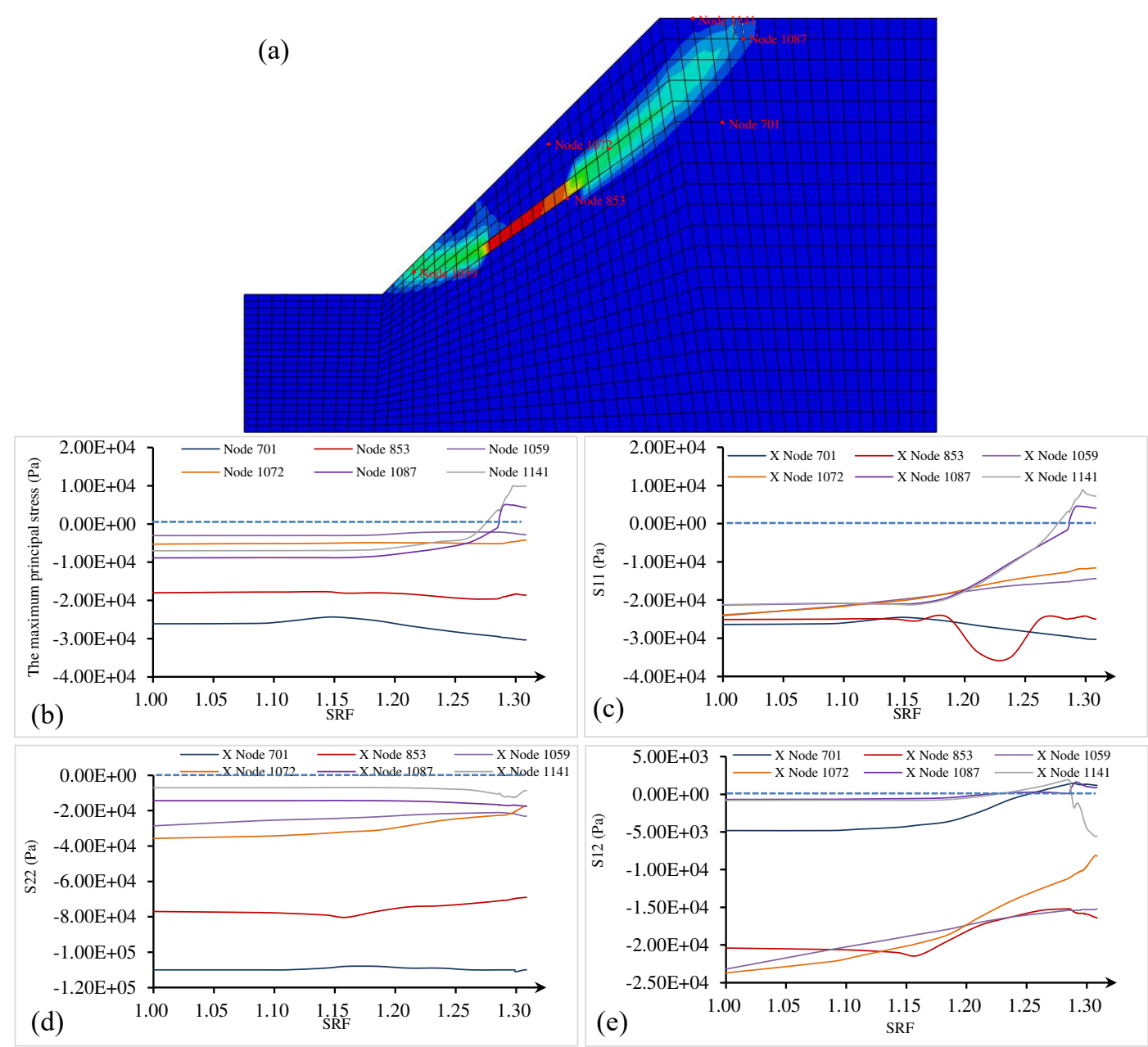

Fig. 10. Stress variation at different positions of slope. (a) Monitoring location of the model, (b) maximum principal stress of the monitoring nodes, (c) S11 of the monitoring nodes, (d) S22 of the monitoring nodes, and (e) S12 of the monitoring nodes.

\section{Conclusions} of $45^{\circ}$ and cohesion of $10 \mathrm{kPa}$. Tensile cracks with different damage parameters or lengths are set at different 
positions in a slope model to achieve the goal. Some conclusions are drawn from the simulation.

1). The MAXPS based on XFEM well simulates the tensile behavior of soil. The XFEM model can automatically search the position of cracks according to the stress field, avoiding pre-existing cracks in LEM, and in the XFEM model the crack can develop with the computation. The FOS of the slope considering tensile cracks is slightly smaller than the FOS of the slope without considering tensile cracks.

2). When the potential slip surface starts to penetrate, a tensile crack appears at the slope crown while swelling occurs at the foot of the slope. The phenomenon can be considered as a signal of metastability of soil slope before complete failure.

3). The initial stress state of a slope is at a compressive state. With slope deformation, the tension zone appears on the upper of slope when the potential slip surface starts to penetrate. The stress field illustrates the question in Tang's literature (Tang et al., 2019) why the depth of a crack cannot develop downward without limitation.

4). Most of the tensile cracks in slopes hardly affect the slope stability. This is because of the compressive stress state existing in most part of the slope. However, there are still two kinds of tensile cracks can affect original slip surface or slope stability, cracks located in the tension zone or cracks passing through the potential plastic zone with a long length.

5). During crack propagation, one tip of the crack transmits stress, and the other tip accumulates stress and strain. The direction of propagation is from the transmitted tip to the accumulated tip, and accumulated stress is released when the crack propagates to the ground surface.

These conclusions can guide the practical engineering in some aspects. For example, it is difficult to determine the tensile strength of soil slopes. However, researchers can obtain the tensile parameters of soil by calibrated the position of crown cracks based on the numerical simulation of slope stability. And researchers 
can evaluate the extent of slope deformation by comparing the depth of crown cracks or the depth of drop heads between the actual slope and numerical model.

It is noted that the slope model in the case has a toe angle of $45^{\circ}$ and cohesion of $10 \mathrm{kPa}$, representing one type of soil slide (Fig.1). If a slope is mainly composed of sand, with lower cohesion or tensile strength, or has steeper angle, it's more prone to collapse (Tang et al., 2019). And above conclusions are based on the condition that seepage in cracks is not considered. Actually, water easily penetrates into the crack (Chen et al., 2019), causing crack propagation (Zhou et al., 2009), and even lead to the landslide (Zhang et al., 2012). In addition, water seepage along the crack will cause an increase in pore water pressure in the lower soil and produce lubrication, thus macroscopically demonstrating that the shear strength in lower soil is reduced. How to consider these complex interactions and behavior in a numerical model is still a difficult and challenging work.

\section{Declarations}

Conflict of interest The authors have no financial or proprietary interests in any material discussed in this article.

\section{Acknowledgements}

This study was funded by the Strategic Priority Research Program of the Chinese Academy of Sciences (Grant No. XDA20030301), National Natural Science Foundation (41790432), and the fellowship of China Postdoctoral Science Foundation (No.2020M683369).

\section{References}

1. Areias, P.P., Rabczuk, T.T., Disa-da Costa, D,D., 2013. Element-wise fracture algorithm using the screened 
poisson equation and local remeshing. Eng. Fract. Mech. 110, 113-137.

2. Areias, P.P., Reinoso, J.J., Camanho, P,P., Rabczuk, T.T., 2015. A constitutive-based element-by-element crack propagation algorithm with local mesh refinement. Comput. Mech. 56 (2), 291-315.

3. Bao, Y., Han, X., Chen, J., Zhang, W., Zhan, J., Sun X., Chen, M., 2019. Numerical assessment of failure potential of a large mine waste dump in Panzhihua City, China. Engineering Geology 253,171-183.

4. Bao, Y., Zhai, S., Chen, J., Xu, P., Sun, X., Zhan, J., Zhang, W., Zhou, X., 2020. The evolution of the Samaoding paleolandslide river blocking event at the upstream reaches of the Jinsha River, Tibetan Plateau. Geomorphology 351. https://doi.org/10.1016/j.geomorph.2019.106970

5. Bhandari, T., Hamad, F., Moormann, C., Sharma, K. G., Westrich, B., 2016. Numerical modelling of seismic slope failure using mpm. Computers and Geotechnics, 75, 126-134.

6. Bishop, A.W., 1973. The stability of tips and spoil heaps. Journal of Experimental Biology (6): 185161.https://doi.org/10.1144/GSL.QJEG.1973.006.03.15

7. Causarano, H., 1993. Factors affecting the tensile strength of soil aggregates. Soil and Tillage Research, $28,15-25$

8. Cai G, Che R, Kong X, Liu C, Zhao C (2017) Experimental investigation on tensile strength of unsaturated fine sands. Journal of Hydraulic Engineering (48): 623-631 (In Chinese).

9. Chen, H., Qin, S., Xue, L., Yang, B., Zhang, K., 2018a. A physical model predicting instability of rock slopes with locked segments along a potential slip surface. Engineering Geology 242, 34-43.

10. Chen, K., Wu, J., 2018b. Simulating the failure process of the Xinmo landslide using discontinuous deformation analysis. Engineering Geology 239, 269-281.

11. Chen, Z., Song, D., Hu, C., Ke, Y., 2019. The September 16, 2017, Linjiabang landslide in Wanyuan County, China: preliminary investigation and emergency mitigation. Landslides. DOI 10.1007/s10346- 
12. Conte, E., Pugliese, L., Troncone, A., 2019. Post-failure stage simulation of a landslide using the material point method. Engineering Geology 253, 149-159.

13. Fan, X., Xu, Q., Gianvito, S., Zheng, G., Huang, R., Dai, L., Ju, Y., 2018., The "long” runout rock 
21. Jiang, Q., Qi, Z., Wei, W. \& Zhou, C.B. 2015. Stability assessment of a high rock slope by strength reduction finite element method. Bulletin of Engineering Geology and the Environment, 74, 1153-1162.

22. Koerner, R.M., Soong, T.Y., 2000. Stability Assessment of Ten Large Landfill Failures. Geo-Denver, 1-38.

23. Konrad, J.M., Ayad, R., 1997. An idealized framework for the analysis of cohesive soils undergoing desiccation. Canadian Geotechnical Journal 34(4), 477-488.

24. Lei, H., Liu, X., Song, Y., Xu, Y., 2021. Stability analysis of slope reinforced by double-row stabilizing piles with different locations. Natural Hazards 106, 19-42.

25. Li, L., Wang, Y., Zhang, L., Choi, C., Ng, CWW., 2019. Evaluation of Critical Slip Surface in Limit Equilibrium Analysis of Slope Stability by Smoothed Particle Hydrodynamics. International Journal of Geomechanics 19, 5.

26. Liu, X., Wang, Y., Li, D., 2019. Investigation of slope failure mode evolution during large deformation in spatially variable soils by random limit equilibrium and material point methods. Computers and Geotechnics, 301-312.

27. Lo, C., Lin, M., Tang, C., Hu, C., 2011. A kinematic model of the Hsiaolin landslide calibrated to the morphology of the landslide deposit. Engineering Geology 123, 22-39.

28. Ma, G.W., An, X.M., Zhang, H.H., Li, L.X., 2009. Modeling complex crack problems using the numerical manifold method. Int. J. Fract. 156:21-35

29. Matsui, T., San, KC., 1992. Finite element slope stability analysis by shear strength reduction technique. Soils and Foundations32, 59-70.

30. Michalowski, R.L., 2012. Cracks in slopes: limit analysis approach to stability assessment. GeoCongress 2012: State of the Art and Practice in Geotechnical Engineering. ASCE, pp. 442-450. 
31. Michalowski, R.L., 2013. Stability assessment of slopes with cracks using limit analysis. Can. Geotech. J. $50,1011-1021$.

32. Moës, N., Dolbow, J., Belytschko, T., 1999. A finite element method for crack growth without remeshing. International Journal for Numerical Methods in Engineering 46, 131-150.

33. Munkholm, L.J., Schjønning, P., Kay, B.D., 2002. Tensile strength of soil cores in relation to aggregate strength, soil fragmentation and pore characteristics. Soil \& Tillage Research (64), 125-135.

34. Niant, K., Huanger, Q., Wans, S. Cheng, Q. 2012. Three-dimension strength reduction finite element analysis of slopes: geometric effects. Canadian Geotechnical Journal, 49, 574-588

35. Ouyang, C., An, H., Zhou, S., Wang, Z., Su, P., Wang, D., Cheng, D., She, J., 2019 Insights from the failure and dynamic characteristics of two sequential landslides at Baige village along the Jinsha River, China. Landslides DOI 10.1007/s10346-019-01177-9

36. Peron, H., Hueckel, T., Laloui, L., Hu, L.B., 2009. Fundamentals of desiccation cracking of finegrained soils: experimental characterization and mechanisms identification. Canadian Geotechnical Journal 46(1), 1177-1201.

37. Qu, G., Hinchberger, S.D., Lo, K.Y., 2009. Case studies of three-dimensional effects on the behaviour of test embankments. Canadian Geotechnical Journal 46, 1356-1370.

38. Rabczuk, T., Ren, H., 2017. A peridynamics formulation for quasi-static fracture and contact in rock. Engineering Geology 225, 42-48.

39. Ray, R., Deb, K., Shaw, A., 2019. Pseudo-Spring smoothed particle hydrodynamics (SPH) based computational model for slope failure. Engineering Analysis with Boundary Elements 101, 139-148. 
40. Sanborn, S.E., Jean H, P., 2011. Frictional slip plane growth by localization detection and the extended finite element method (XFEM). International Journal for Numerical \& Analytical Methods in Geomechanics 35, 11, 1278-1298.

41. Seed, R.B., Mitchell, J.K., Seed, H.B., 1990. Kettleman Hills Waste Landfill Slope Failure. II: Stability Analyses. Journal of Geotechnical and Geoenvironmental Engineering 116, 669-690.

42. Shen, J., Karakus, M., 2014. Three-dimensional numerical analysis for rock slope stability using shear strength reduction method. Canadian Geotechnical Journal 51, 164-172.

43. Shi, G.-H., 1991. Manifold method of material analysis. Transaction of the $9^{\text {th }}$ Army Conference on Applied Mathematics and Computing. Minneapolis, Minnesota, USA, pp, 57-76

44. Solari, L., Raspini, F., Del Soldato, M., Bianchini, S , Ciampalini, A., Ferrigno, F., et al. 2018. Satellite radar data for back-analyzing a landslide event: the ponzano (central italy) case study. Landslides, 15(4), $773-782$.

45. Steiakakis, E., Kavouridis, K., Monopolis, D., 2009. Large scale failure of the external waste dump at the “South Field” lignite mine, Northern Greece. Engineering Geology 104, 269-279.

46. Tamarkar, S.B., Totosawa, Y., Itoh, K., 2005. Tensile Strength of Soil Measured Using Newly Developed Tensile Strength Apparatus. Research Reports of the National Institute of Industrial Safety.

47. Tang, C., Hu, J., Lin, M., Angelier, J., Lu, C., Chan. Y., Chu, H., 2009. The Tsaoling landslide triggered by the Chi-Chi earthquake, Taiwan: insights from a discrete element simulation. Eng Geol 106, 1-19.

48. Tang, L., Zhao, Z., Luo, Z., Sun, Y., 2019. What is the role of tensile cracks in cohesive slopes?. Journal of Rock Mechanics and Geotechnical Engineering 11, 314-324. 
49. Wang, G.H., Wang, Y.X, Lu, W.B., Zhou, C.B, Chen, M., Peng, Y., 2015. XFEM based seismic potential failure mode analysis of concrete gravity dam-water-foundation system through incremental dynamic analysis. Engineering Structures 98, 81-94.

50. Wu, L.Z., Zhou, Y., Sun, P., Shi, J.S., Liu, G.G., Bai, L.Y., 2017. Laboratory characterization of rainfallinduced loess slope failure. Catena 150, 1-8.

51. Xu, Q., Zheng, G., Li, W., He, C., Dong, X., Guo, X., Feng, W., 2018. Study on successive landslide damming events of Jinsha River in Baige Village on Octorber 11 and November 3. Journal of Engineering Geology, 26, 1534-1551.

52. Yin, Y.P., Li, B., Wang, W.P., Zhan, L.T., Xue, Q., Gao, Y., Zhang, N., Chen, H.Q., Liu, T.K., Li, A.G., 2016. Mechanism of the december 2015 catastrophic landslide at the Shenzhen landfill and controlling geotechnical risks of urbanization. Engineering 2, 230-249.

53. Zhang, F., Yan, B., Feng, X., Lan, H., Kang, C., Lin, X., Zhu, X., Ma, W., 2019a. A rapid loess mudflow triggered by the check dam failure in a bulldoze mountain area, Lanzhou, China. Landslides 10, 19811992.

54. Zhang, G., Wang, R., Qian, J., Zhang, J., Qian, J., 2012. Effect study of cracks on behavior of soil slope under rainfall conditions. Soils and Foundations 52, 4, 634-643.

55. Zhang, H., Zhu, J., Wang, J., Yuan, Y., Feng, Lin., 2006. Experimental study of tensile strength of compacted gravel soil. Chinese Journal of Rock Mechanics and Engineering 25, 4186-4190.

56. Zhou, J., Wang, J.Q., Zeng, Y., Zhang, J., 2009. Simulation of slope stability analysis by particle flow code. Rock Soil Mech 30(1), 86-90.

57. Zhou, X., Chen, J., 2019. Extended finite element simulation of step-path brittle failure in rock slopes with non-persistent en-echelon joints. Engineering Geology 250, 65-88. 

slope subjected to water infiltration. Landslide 6, 299-308.

461

462 


\section{Lists of figures}

Fig. 1. Crown cracks appear in some soil slopes. (a) A potential landslide with obvious deformation in Jilin province in 2016, (b) a potential landslide in a waste dump in Sichuan province in 2016, (c) a potential landslide with obvious deformation in Jilin province in 2015, and (d) a potential landslide in Liaoning province in 2019. Red Arrows denote to the direction of slides.

Fig. 2. Principles of the extended element method. (a) Sketch of a discontinuous element in the XFEM, (b) illustration of phantom node method.

Fig. 3. Mechanical characteristics of the tensile crack of soil. (a) A sketch of tensile failure of materials, (b) an example of tensile stress-displacement curve of soil (modified from Tamrakar et al., 2005).

Fig. 4. Comparison result of real and simulation tensile tests. (a)-(d) Propagation of crack during the stretching based on the stress result, (e) tensile test in Tamrakar's study (Tamrakar et al., 2005).

Fig. 5. Results of stability analysis. (a) Dimensions of the slope model, (b) and (d) magnitude of the plastic strain, (c) and (e) magnitude of the total displacement.

Fig. 6. Propagation of a tensile crack in a soil slope failure. (a), (c), (e), and (g) incorporate the contour map of plastic strain magnitude; (b), (d), (f), and (h) incorporate the contour map of maximum principal stress.

Fig. 7. Morphology of tensile crack at the time of a slope failure under different soil damage strengths. (a), (c), (e), and (g) the magnitude of plastic strain; (b), (d), (f), and (h) the magnitude of total displacement.

Fig. 8. Sensitivity analysis for crack propagation in different conditions based on the contour map of plastic strain magnitude.

Fig. 9. Sensitivity analysis for crack propagation in different conditions based on the contour map of stress magnitude.

Fig. 10. Stress variation at different positions of slope. (a) Monitoring location of the model, (b) maximum 

and (e) S12 of the monitoring nodes.

487

Lists of tables

488 Table.1 A brief summary for tensile strength of soil aggregates 


\section{Figures}

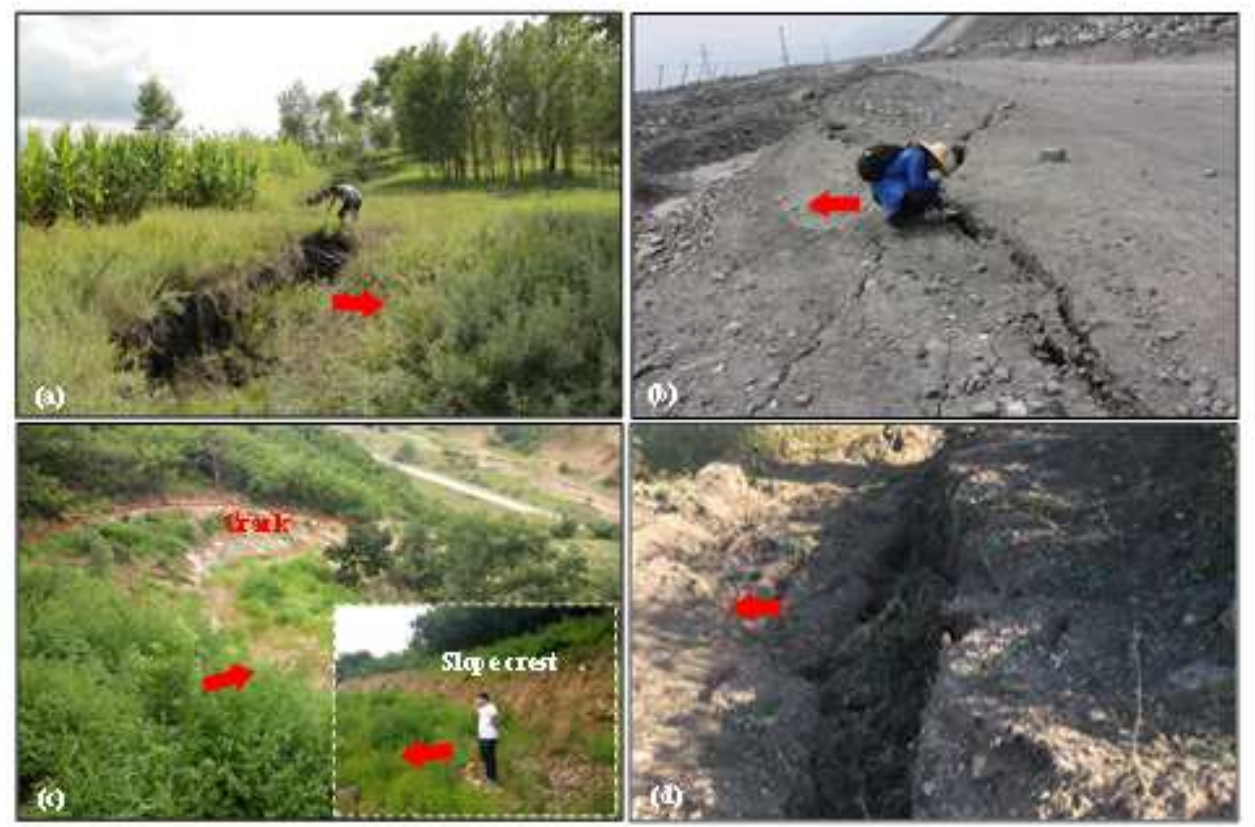

\section{Figure 1}

Crown cracks appear in some soil slopes. (a) A potential landslide with obvious deformation in Jilin province in 2016, (b) a potential landslide in a waste dump in Sichuan province in 2016, (c) a potential landslide with obvious deformation in Jilin province in 2015, and (d) a potential landslide in Liaoning province in 2019. Red Arrows denote to the direction of slides.
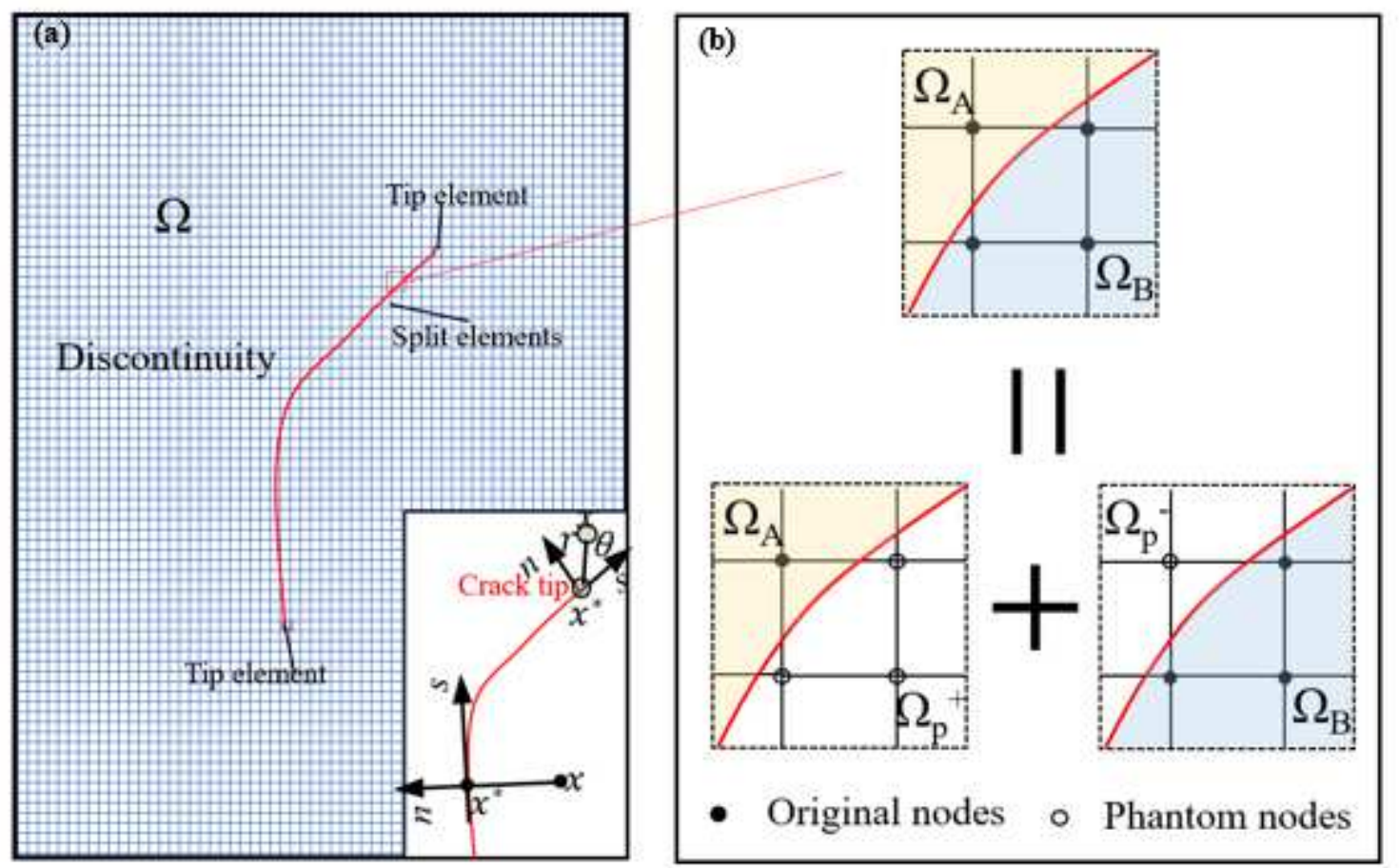

Figure 2 
Principles of the extended element method. (a) Sketch of a discontinuous element in the XFEM, (b) illustration of phantom node method.
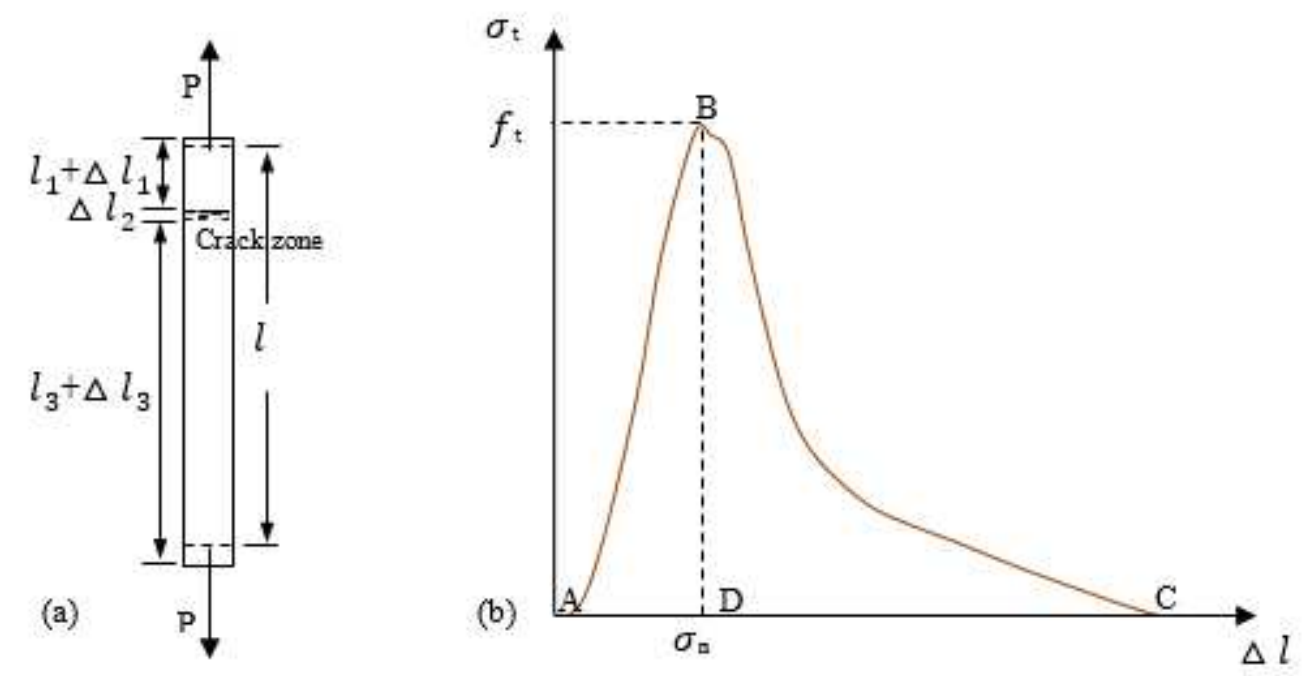

\section{Figure 3}

Mechanical characteristics of the tensile crack of soil. (a) A sketch of tensile failure of materials, (b) an example of tensile stress-displacement curve of soil (modified from Tamrakar et al., 2005). 

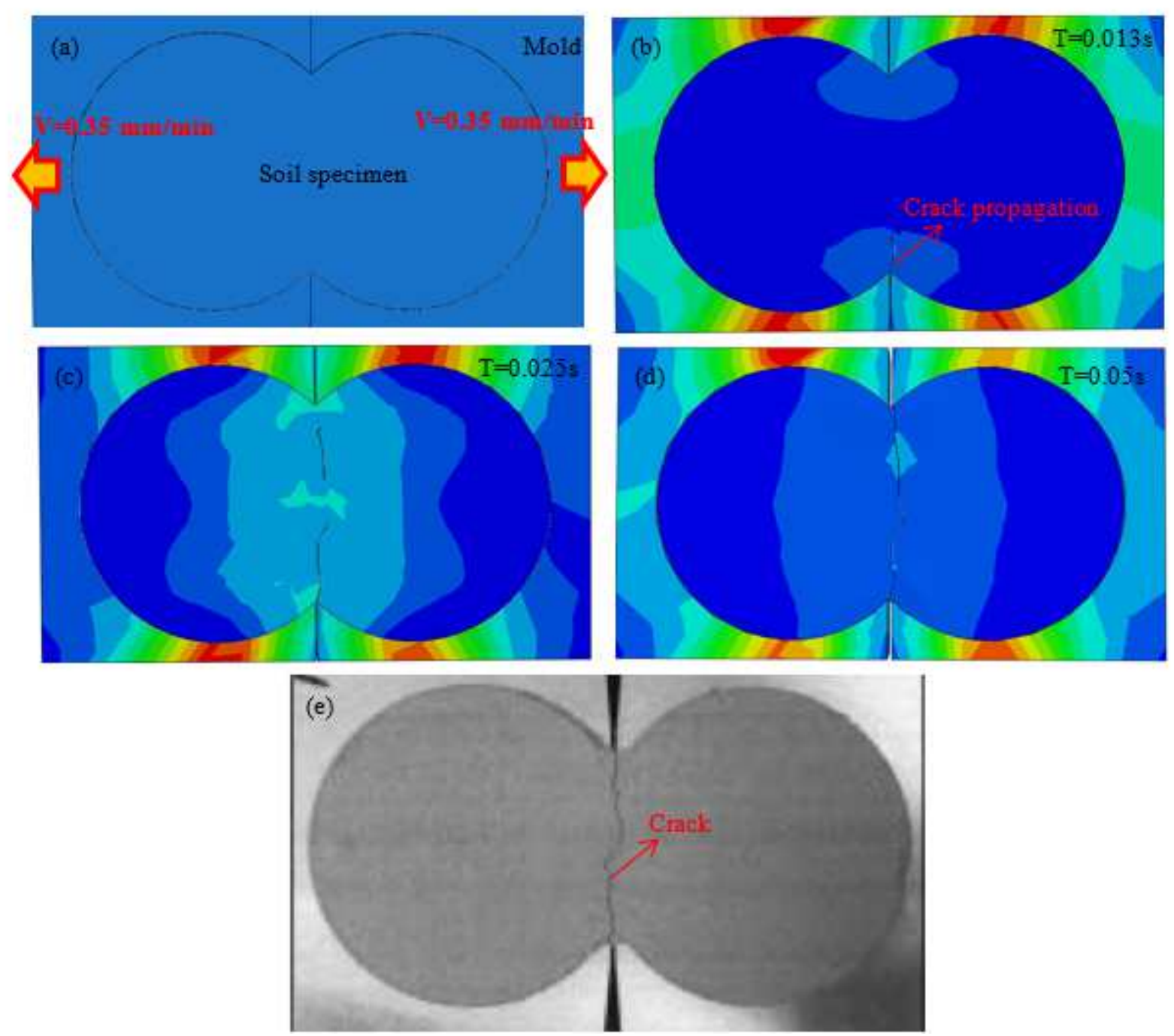

\section{Figure 4}

Comparison result of real and simulation tensile tests. (a) -(d) Propagation of crack during the stretching based on the stress result, (e) tensile test in Tamrakar's study (Tamrakar et al., 2005). 


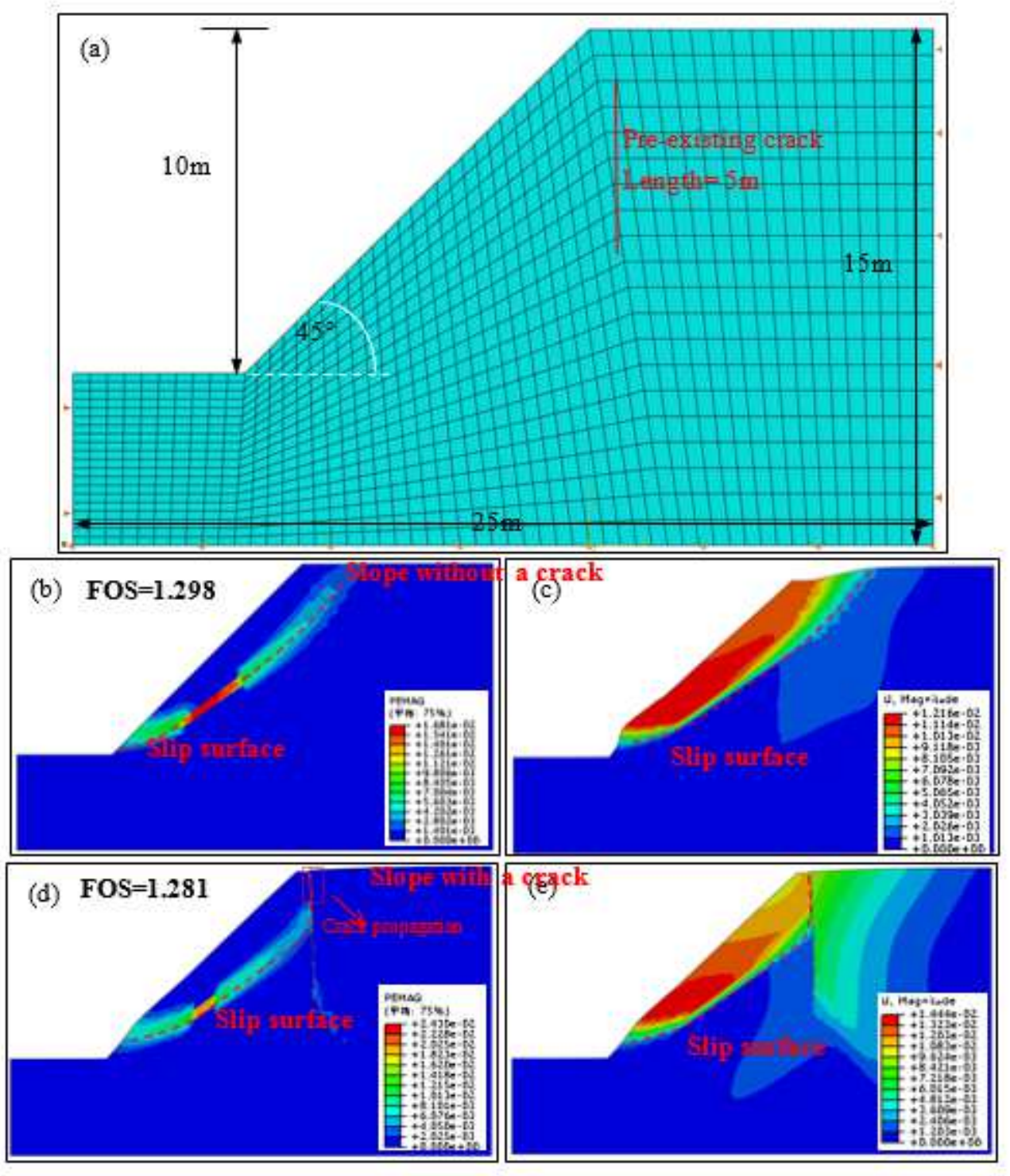

Figure 5

Results of stability analysis. (a) Dimensions of the slope model, (b) and (d) magnitude of the plastic strain, (c) and (e) magnitude of the total displacement. 


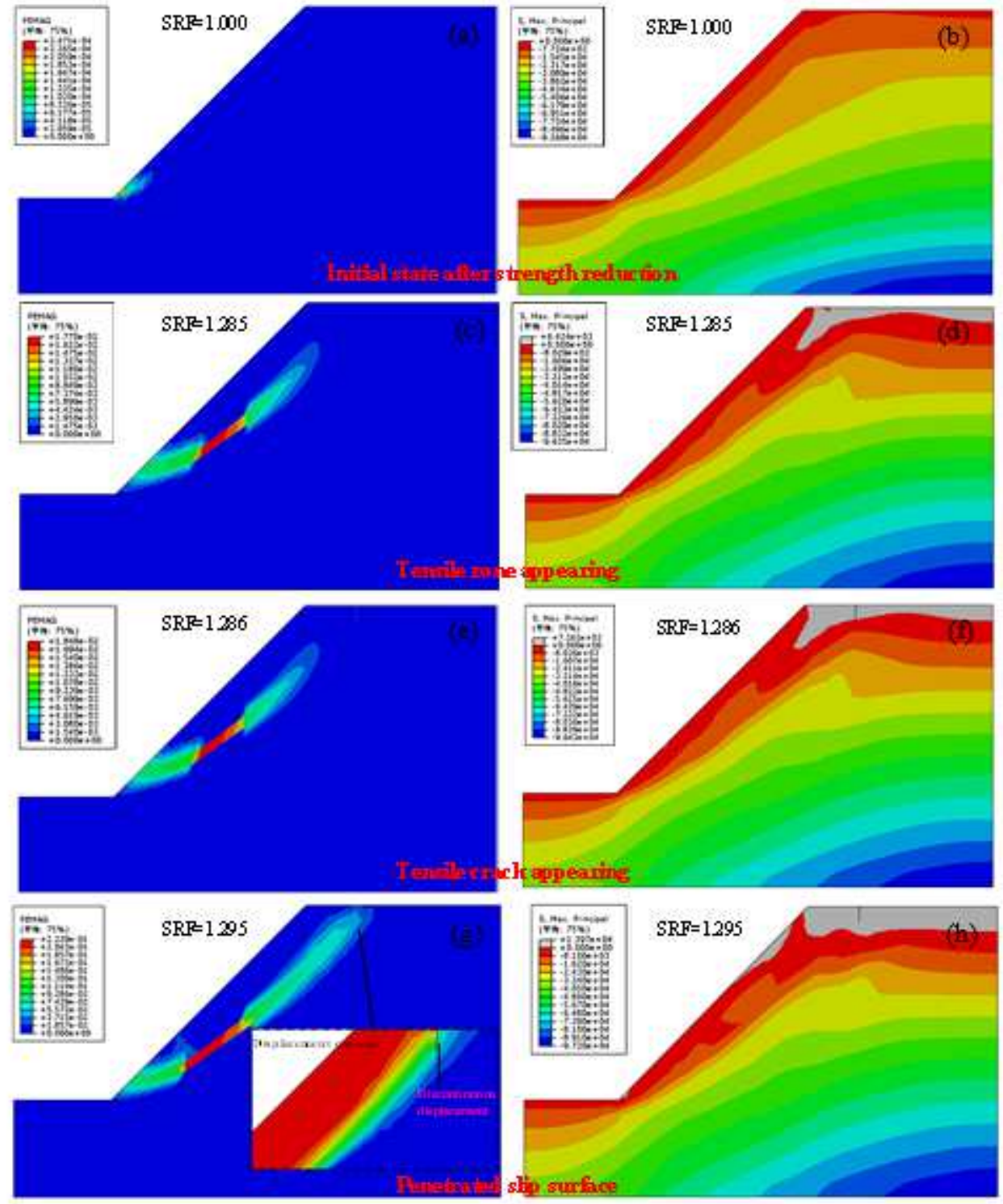

Figure 6

Propagation of a tensile crack in a soil slope failure. (a), (c), (e), and (g) incorporate the contour map of plastic strain magnitude; (b), (d), (f), and (h) incorporate the contour map of maximum principal stress. 


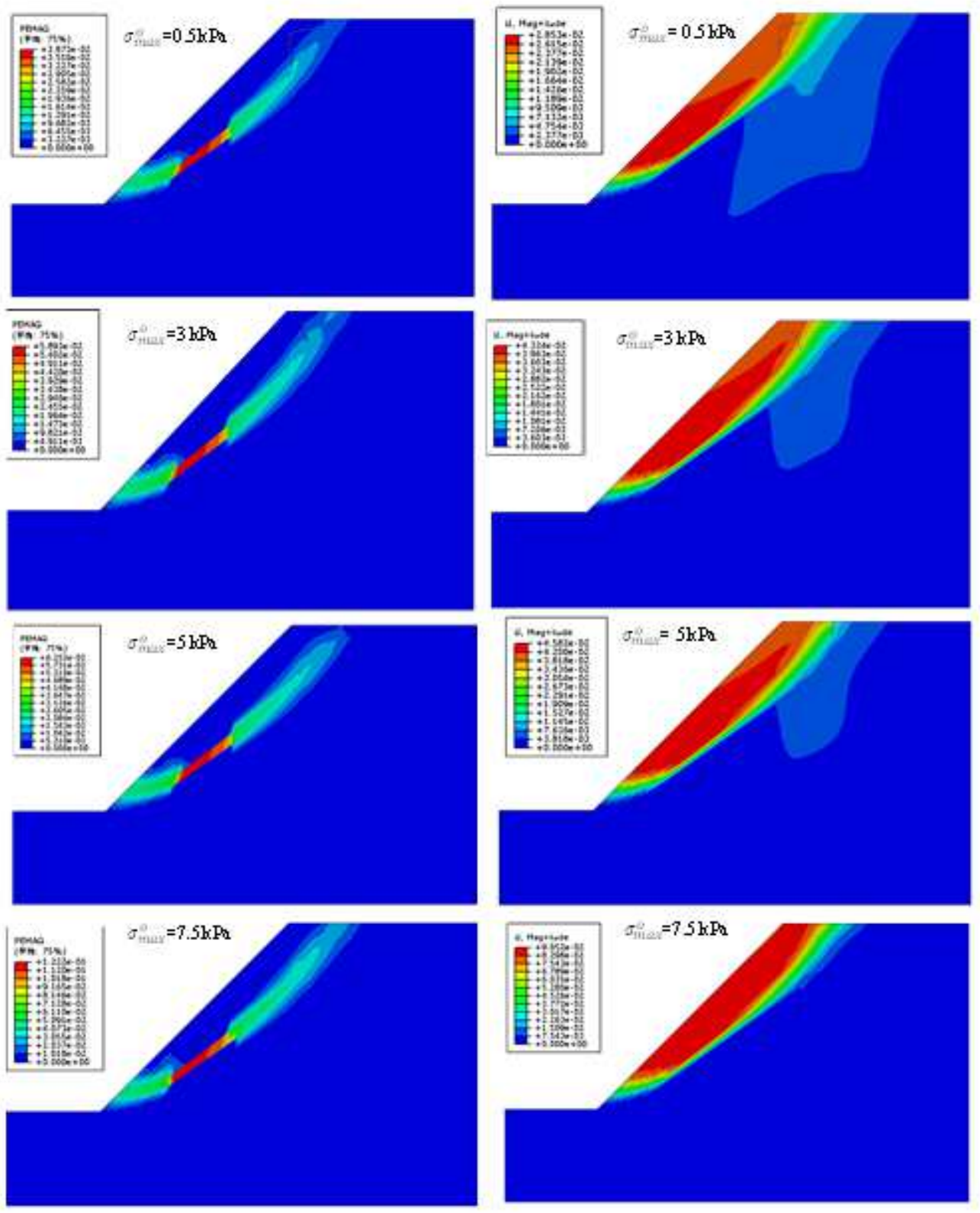

Figure 7

Morphology of tensile crack at the time of a slope failure under different soil damage strengths. (a), (c), $(e)$, and (g) the magnitude of plastic strain; (b), (d), (f), and (h) the magnitude of total displacement. 

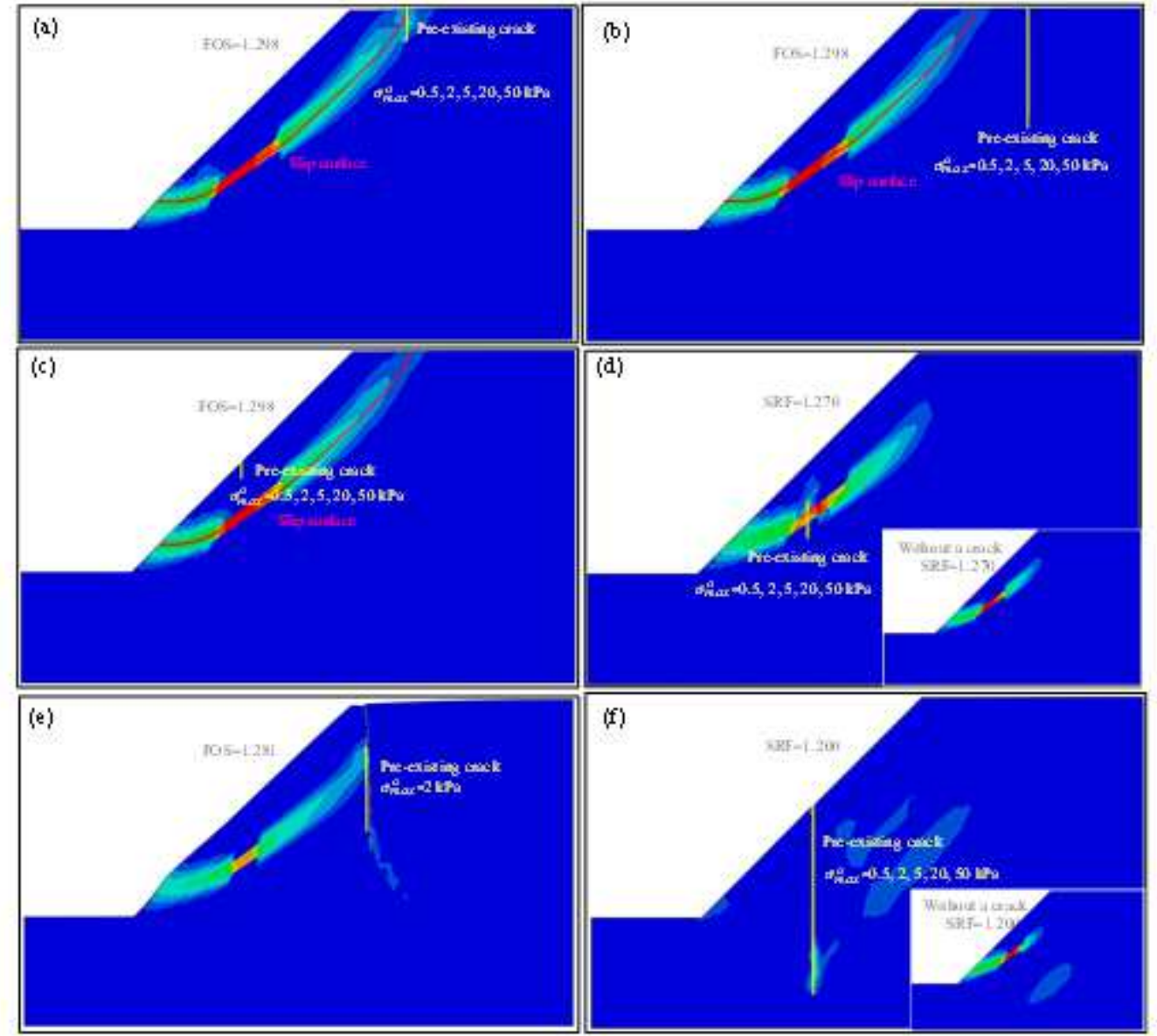

Figure 8

Sensitivity analysis for crack propagation in different conditions based on the contour map of plastic strain magnitude. 


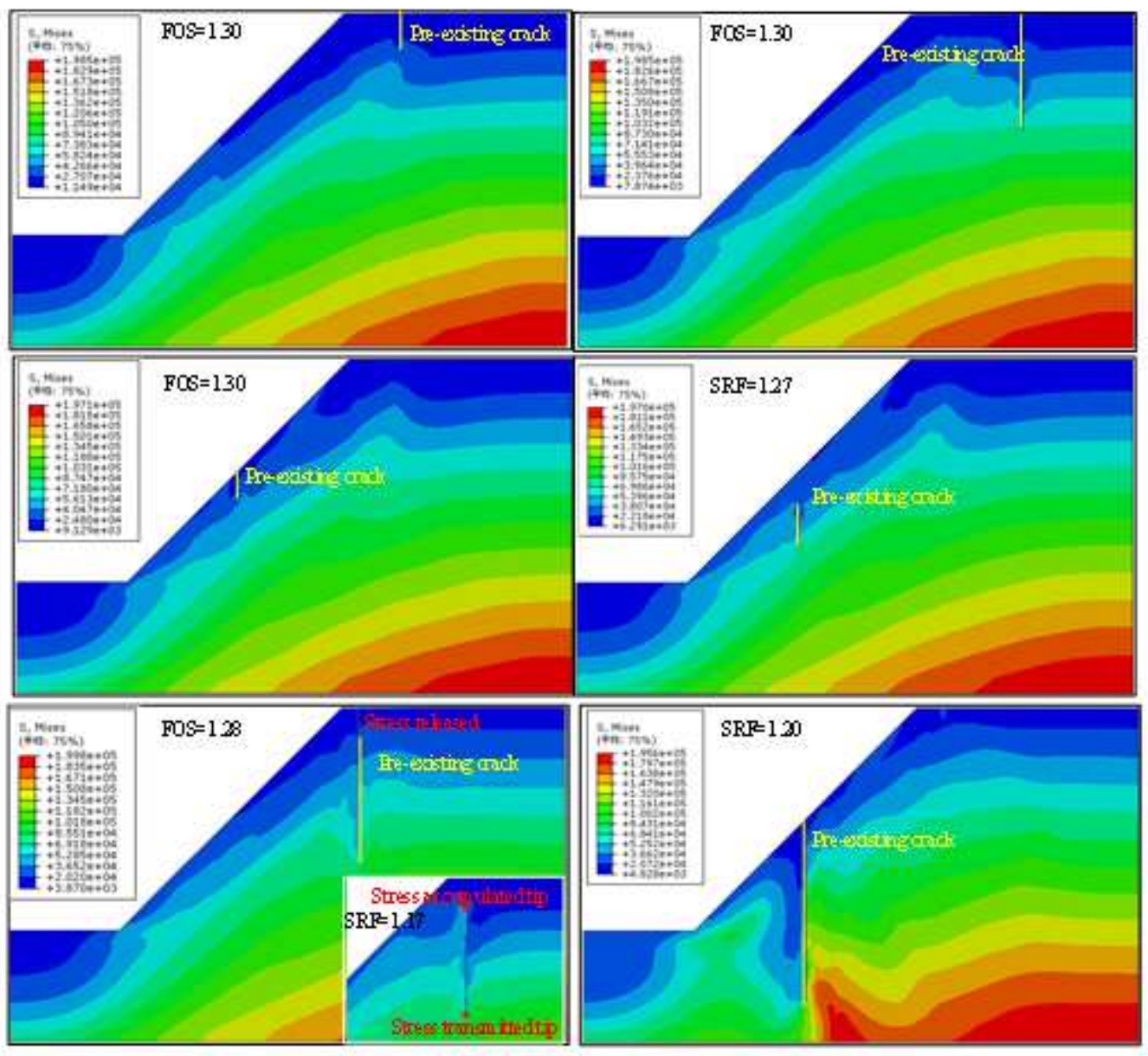

Figure 9

Sensitivity analysis for crack propagation in different conditions based on the contour map of stress magnitude. 


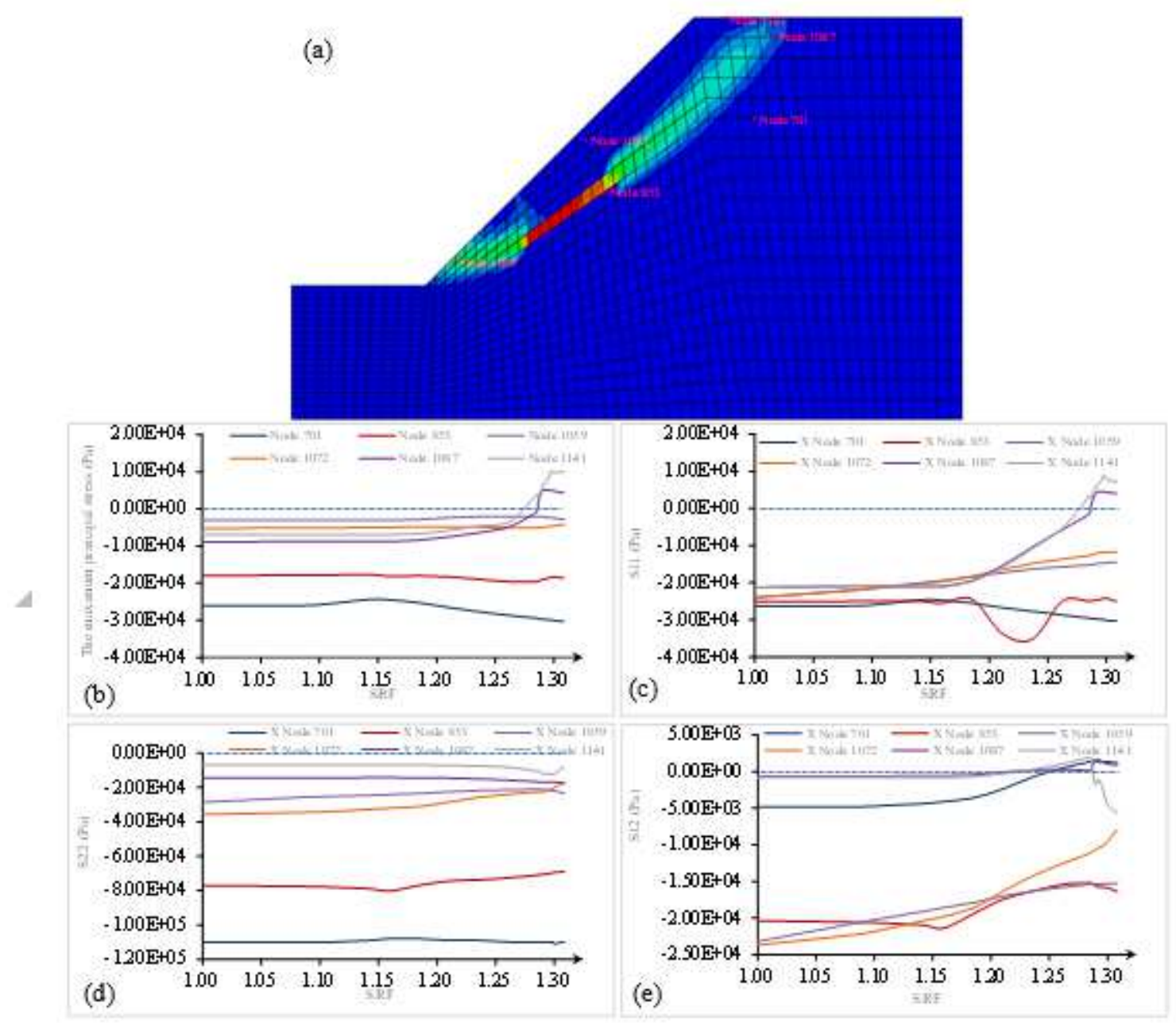

\section{Figure 10}

Stress variation at different positions of slope. (a) Monitoring location of the model, (b) maximum principal stress of the monitoring nodes, (c) S11 of the monitoring nodes, (d) S22 of the monitoring nodes, and (e) S12 of the monitoring nodes. 